\title{
Gene Family Analysis of the Arabidopsis NF-YA Transcription Factors Reveals Opposing Abscisic Acid Responses During Seed Germination
}

\author{
Chamindika L. Siriwardana • Roderick W. Kumimoto • \\ Daniel S. Jones • Ben F. Holt III \\ Published online: 25 February 2014 \\ (C) The Author(s) 2014. This article is published with open access at Springerlink.com
}

\begin{abstract}
In the plant kingdom, each of the NUCLEAR FACTOR-Y $(N F-Y)$ transcription factor families, $N F-Y A, N F-$ $Y B$, and $N F-Y C$, has undergone a great expansion compared to the animal kingdom. For example, Arabidopsis thaliana has 10 members of each gene family compared to only one in humans. Progress towards understanding the significance of this expansion is limited due to a lack of studies looking at the complete gene family during plant development. In the current study, transgenic overexpression lines were created for all 10 Arabidopsis NF-YA genes and examined for general development and alterations in abscisic acid (ABA)-mediated seed germination. NF-YA overexpression typically led to severe growth retardation and developmental defects, which extended from embryogenesis through to adult plants. Although overexpression of all $N F-Y A$ family members consistently led to growth retardation, some transgenic lines were hypersensitive to ABA during germination while others were hyposensitive. The opposing germination phenotypes were associated with the phylogenetic relationships between the $N F-Y A$ members. In addition, ABA marker genes were
\end{abstract}

Electronic supplementary material The online version of this article (doi:10.1007/s11105-014-0704-6) contains supplementary material, which is available to authorized users.

C. L. Siriwardana $\cdot$ R. W. Kumimoto · D. S. Jones •

B. F. Holt III $(\square)$

Department of Microbiology and Plant Biology, University of

Oklahoma, 770 Van Vleet Oval, GLCH, Room 43, Norman,

OK 73019, USA

e-mail: benholt@ou.edu

C. L. Siriwardana

e-mail: Chamindika.L.Siriwardana-1@ou.edu

R. W. Kumimoto

e-mail: Roderick.W.Kumimoto-1@ou.edu

D. S. Jones

e-mail: danielsjones552@ou.edu misregulated and $\mathrm{ABA}$ induction of gene expression was reduced in the overexpressors. Collectively, this study demonstrates that although NF-Ys have retained high degrees of similarity, they have evolved unique and sometimes opposing roles during plant development.

Keywords Germination · Abscisic acid · Signaling · Transcription factor $\cdot$ Plant hormone $\cdot$ NUCLEAR FACTOR-Y

\section{Introduction}

NUCLEAR FACTOR-Y (NF-Y) transcription factors bind DNA as complexes composed of three unique subunits, called NF-YA, NF-YB, and NF-YC. While common throughout the eukaryotic lineage, the three NF-Y families have undergone an expansion in plants, with most species encoding $\sim 10$ genes for each family (Gusmaroli et al. 2001, 2002; Stephenson et al. 2007; Thirumurugan et al. 2008; Siefers et al. 2009; Cao et al. 2011; Petroni et al. 2012; Laloum et al. 2013). A. thaliana (Arabidopsis) has $10 \mathrm{NF}-\mathrm{YA}, 10 \mathrm{NF}-\mathrm{YB}$, and $10 \mathrm{NF}-\mathrm{YC}$, and since NF-Y binds to DNA as a heterotrimer, this leads to the possibility of 1,000 unique NF-Y transcription factors (Petroni et al. 2012). The large number of possible complexes suggests the potential to regulate diverse plant processes. NF-Ys have demonstrated roles in abscisic acid (ABA) responses (Nelson et al. 2007; Warpeha et al. 2007; Li et al. 2008; Yamamoto et al. 2009; Leyva-Gonzalez et al. 2012; Kumimoto et al. 2013; Mu et al. 2013), photoperioddependent flowering (Ben-Naim et al. 2006; Wenkel et al. 2006; Cai et al. 2007; Chen et al. 2007; Kumimoto et al. 2008, 2010), embryogenesis (West et al. 1994; Lotan et al. 1998; Kwong et al. 2003; Lee et al. 2003), endoplasmic reticulum stress responses (Liu and Howell 2010), salt stress 
responses ( $\mathrm{Li}$ et al. 2013), photosynthesis (Kusnetsov et al. 1999; Stephenson et al. 2010), root elongation (Ballif et al. 2011), and nodule development (Combier et al. 2006, 2008; Zanetti et al. 2010).

NF-Y family proteins have retained a high degree of similarity, especially in the residues necessary for complex formation and DNA binding; therefore, how NF-Ys have diverged to regulate a diverse set of development processes is still in question (Siefers et al. 2009; Laloum et al. 2013). NF-YA proteins are typified by a 53-amino acid conserved domain which makes physical contacts with DNA at CCAAT box ciselements and mediates interactions with the NF-YB/NF-YC dimer (Olesen and Guarente 1990; Maity et al. 1992; Xing et al. 1993, 1994; Nardini et al. 2013). While the NF-YB and NF-YC subunits are abundant in vivo, NF-YA is limiting for trimer formation and subsequent DNA binding (Dolfini et al. 2012). A combination of animal and plant literature demonstrated that the expression of NF-YA subunits is highly regulated at the transcriptional, posttranscriptional, and posttranslational level. At the transcriptional level, tissue-specific expression of the expanded $N F-Y A$ gene family in plants has shown spatial and temporal specialization (Stephenson et al. 2007; Siefers et al. 2009; Cao et al. 2011). In animals, NF-YA protein is targeted for ubiquitination and subsequently degraded by proteasome (Manni et al. 2008). Due to the high conservation of the residues targeted for ubiquitination, this likely also holds true for plant NF-YAs. In addition, plant NF-YA transcripts are targeted by a family of microRNAs called miR169 (Rhoades et al. 2002). In turn, miR169 abundance is regulated by the important stress hormone ABA.

Several recent publications have demonstrated that NF-YA subunits play an essential role during ABA-mediated responses in plants. ABA signals are perceived via the PYRABACTIN RESISTANCE1 (PYR1)/PYR1-LIKE (PYL)/REGULATORY COMPONENTS OF ABA RECEPTOR (RCAR) family of soluble receptors (Fujii et al. 2009; Ma et al. 2009; Melcher et al. 2009; Miyazono et al. 2009; Nishimura et al. 2009; Park et al. 2009; Santiago et al. 2009). Once ABA is bound to PYR/PYL, a signaling cascade is initiated through PP2C phosphatases and SnRK2 kinases to activate basic leucine zipper (bZIP) transcription factors that bind ABA response elements (ABREs) within the promoters of ABA response genes (Gosti et al. 1999; Merlot et al. 2001; Saez et al. 2004; Choi et al. 2005; Finkelstein et al. 2005; Furihata et al. 2006; Fujii and Zhu 2009; Rubio et al. 2009; Umezawa et al. 2009; Vlad et al. 2009; Yoshida et al. 2010). Select NF-YA subunits were shown to regulate the expression of these core ABA signaling components (Leyva-Gonzalez et al. 2012). Microarray analysis of Arabidopsis NF-YA2, NF$Y A 3, N F-Y A 7$, and NF-YA10 driven by an inducible promoter revealed that transcript levels of several $P Y R / P Y L / R C A R$, $P P 2 C$, and $S n R K 2$ family members were consistently downregulated.
In addition to regulating $\mathrm{ABA}$ signaling components, mutants and overexpressors of $N F$-YAs have ABA-related developmental phenotypes during drought responses and seed germination. NF-YA5 transcripts increase in response to drought in an ABA-dependent manner ( $\mathrm{Li}$ et al. 2008). The increase in transcript of NF-YA5 is attributed to drought-induced downregulation of miR169a, which targets NF-YA5 transcripts for degradation. Further, plants overexpressing $N F-Y A 5$ were drought tolerant, whereas mutants were susceptible. Two recent publications further demonstrated that overexpression of selected members of the NF-YA family leads to ABA-mediated seed germination phenotypes. Briefly, qualitative analyses demonstrated that overexpression of NF-YA1,NF-YA2,NF-YA3, NF$Y A 7, N F-Y A 9$, and NF-YA10 led to ABA hypersensitivity (Leyva-Gonzalez et al. 2012; Mu et al. 2013). In addition, NF-YA5 mutants were hypersensitive to ABA during seed germination (Warpeha et al. 2007). NF-YC subunits were also recently shown to be involved in $\mathrm{ABA}$ responses. Interestingly, different NF-YC subunits can have unique and opposing functions in ABA-mediated seed germination (Kumimoto et al. 2013). Mutants of NF-YC4 were hypersensitive to ABA, whereas mutants of $N F-Y C 3$ and $N F-Y C 9$ were hyposensitive to ABA during germination. The presence of opposing germination phenotypes in $N F$ $Y C$ mutants indicated that $N F-Y A$ s might also be involved in similar phenomena; however, this had not been systematically examined for the entire family.

Here, we present a complete family analysis of the Arabidopsis NF-YA. All 10 Arabidopsis NF-YA genes were systematically overexpressed, and the resulting phenotypes were characterized relative to morphological development and ABA-mediated germination. Due to the presence of $10 \mathrm{NF}-\mathrm{YA}$ genes with high levels of amino acid similarity and extensive overlap in tissuespecific expression patterns (Siefers et al. 2009), we reasoned that overexpression would be a more fruitful first approach. Additionally, loss-of-function mutants in $N F-Y A 1$ and NF-YA2 are lethal (Pagnussat et al. 2005; Meinke et al. 2008). Overexpression of all NF-YA led to severe growth retardation, which was seen from embryo development through the adult plant. Although all overexpressors showed various levels of growth retardation, some transgenic lines were hypersensitive and others were hyposensitive to germination on ABA. ABA marker genes were misregulated, and the ability of exogenously applied ABA to induce transcription of marker genes was attenuated in the overexpressors. The opposing ABA phenotypes were associated with phylogenetic relationships between the $N F-Y A s$, indicating that members of this closely related gene family evolved distinct roles during ABA-mediated seed germination. 


\section{Materials and Methods}

Phylogenetic Analysis

Full-length cDNA sequences for the coding regions of $N F-Y A$ subunits were obtained from TAIR (http://www.arabidopsis.org (Huala et al. 2001)). Phylogenetic analyses were conducted in MEGA5 (Tamura et al. 2011). The maximum parsimony method was used to infer evolutionary history as described previously (Felsenstein 1985; Nei 2000). The phylogenetic tree is drawn to scale.

\section{Construction of Transgenic Lines}

The full-length coding region of each $N F-Y A$ gene (NF-YA1 to $N F-Y A 9$ ) was amplified from cDNA by PCR using Pfu Ultra II (cat\#600670, Agilent Technologies) and ligated into the Gateway ${ }^{\circledR}$ entry vector pENTR/D-TOPO (cat\#45-0218, Invitrogen). All constructs were sequenced and found to be identical to sequences at The Arabidopsis Information Resource (http://www.arabidopsis.org (Huala et al. 2001)). NF-YA10 cDNA in pDONR221 was obtained from ATOME1 ORFEOME library (stock\#51B10, CNRGV). All $N F-Y A$ cDNA clones were introduced to the plant expression destination vector pEarlyGate102 (stock\#CD3-684, ABRC) (Earley et al. 2006) using the Gateway ${ }^{\circledR}$ LR Clonase IITM reaction kit (cat\#56485, Invitrogen). The 35S cauliflower mosaic virus promoter (p35S) (Kay et al. 1987) was driving the expression of each gene. Transgenic plants were generated using agrobacterium-mediated floral dipping described in previous studies (Clough and Bent 1998). At least two independent homozygous or hemizygous transgenic lines were examined for each NF-YA (Table $\mathrm{S} 1$ ).

\section{Plant Cultivation and Germination Assays}

A. thaliana ecotype Columbia (Col-0) was used as the wild type for all experiments. For morphological studies and generation of matched seed sets, plants were grown in standard long-day conditions (16-h light/8-h dark cycle) in a custom walk-in chamber. Plant growth medium contained equal parts Farfard C2 and Metromix $200\left(17,620 \mathrm{~cm}^{3}\right.$ total soil mixture) supplemented with $40 \mathrm{~g}$ MARATHON pesticide and $3,785 \mathrm{~cm}^{3}$ distilled water with Peter's fertilizer (NPK 20:20:20). Plants were watered with dilute Peter's fertilizer (at 1/10 recommended feeding levels) throughout the growth cycle. For western blot, germination assays, qPCR, and microscopy seed plates were cold-stratified in the dark for $48 \mathrm{~h}$ and placed in a Conviron ATC13 growth chamber at $22{ }^{\circ} \mathrm{C}$ with continuous light.

Germination assays were always performed on matched seed sets that were after ripened for 4 months. Seeds were sterilized by treating with $70 \%$ ethanol for $5 \mathrm{~min}$ and $50 \%$ household bleach for $5 \mathrm{~min}$ followed by five washes of sterile distilled water. Seeds were germinated on Gamborg's B5 media or B5 supplemented with (+)-ABA (cat\#A4906, Sigma). Germination was scored as the emergence of the radical tip from the seed coat (Bewley 1997). These experiments were done in triplicate $(n=3)$, with a total of at least 80 seeds used per genotype and repeated three times with independent, matched seed sets with the same results. For the statistical analysis, the observed frequencies were compared with expected frequencies with Fisher's exact tests as previously described within INSTAT (GraphPad Software, La Jolla, CA) (Kumimoto et al. 2013).

\section{Microscopy}

p35S::NF-YA5 and $p N F-Y A:: G U S / G F P$ lines (Siefers et al. 2009) were imaged with a Zeiss Axio Imager.Z1/ApoTome microscope (Carl Zeiss). Prior to imaging, $p N F-Y A$ : GUS/GFP seed coats (including endosperm) and embryos were stained by placing in beta-glucuronidase (GUS) staining solution and incubated overnight at $37^{\circ} \mathrm{C}$ in the dark (Perry and Wang 2003). Subcellular localization was determined in 4-day-old seedlings counterstained by incubating in $50 \mu \mathrm{g} / \mathrm{mL}$ propidium iodide (PI) for $5 \mathrm{~min}$, followed by washing in deionized (DI) water for $5 \mathrm{~min}$. Seedlings were mounted in DI water, and roots were imaged using a Leica TCS SP8 confocal laser scanning microscope with a $\times 40$ water immersion objective. Sequential scanning mode was used for cyan fluorescence protein (CFP) and PI detection where CFP was excited using $458 \mathrm{~nm}$ laser with emission detected at 462 $536 \mathrm{~nm}$ and PI was excited using a 561-nm laser with emission detected at 582-673 nm. Approximately 200 serial sections of root tip were imaged with an average cubic voxel size of $190 \times 190 \times 190 \mathrm{~nm}$ starting with the root epidermis closest to the coverslip imaging through to the stele. For DNA labeling, tissue was fixed in $4 \%$ PFA in PBS for 2 min incubated in $5 \mu \mathrm{g} / \mathrm{mL}$ Hoechst 33342 for 50 min, mounted on DI water, and excited with a 405-nm laser. Images were processed using ImageJ 1.46r (http://rsb.info.nih.gov/ij/) (Schneider et al. 2012) where average intensities of both CFP and PI channels through the series were taken and merged.

\section{Western Blot}

Total protein was extracted from 14-day-old plants by grinding in lysis buffer (20 mM Tris, $\mathrm{pH} 8.0,150 \mathrm{mM} \mathrm{NaCl}, 1 \mathrm{mM}$ EDTA, pH 8.0, $1 \%$ Triton X-100, $1 \%$ SDS with fresh $5 \mathrm{mM}$ DTT, and $100 \mu \mathrm{M}$ MG132). NF-YA-CFP/HA was probed with high-affinity anti-HA primary antibody (cat\#11 867 423 001, Roche) and goat anti-rat secondary antibody (cat\#SC-2032, Santa Cruz Biotechnology). The Bio-Rad ChemiDoc XRS imaging system was used for visualizing the protein blot after incubations with ECL plus reagent 
(cat\#RPN2132, GE Healthcare). Equivalent loading and transfer efficiency was determined by staining the protein blot with Ponceau S (cat\#P3504, Sigma-Aldrich).

\section{qPCR Analysis}

Matched seed sets were germinated on Gamborg's B5 medium, with or without $1 \mu \mathrm{M}(+)$-ABA. Total seed RNA was extracted using the E.Z.N.A. Plant RNA Kit (cat\#R6827-01, Omega Bio-Tek) according to the manufacturer's instructions for difficult samples. Genomic DNA was digested during RNA extraction by treating the columns with DNase (cat\#E1091. Omega Bio-Tek). First-strand cDNA was synthesized using the SuperScript III First-Strand Synthesis System (cat\#18080-051, Invitrogen). qPCR was performed using a CFX Connect ${ }^{\mathrm{TM}}$ Real-Time PCR Detection System (Bio-Rad) with the SYBR Green qPCR Master Mix (cat\#K0222, Fermentas). Gene expression analysis was done using the CFX Manager ${ }^{\mathrm{TM}}$ software (Bio-Rad). Normalized expression, $\Delta \Delta C_{\mathrm{q}}$, was selected as the analysis mode. Samples were normalized to a constitutively expressed reference gene, At2g32170 (Czechowski et al. 2005). Three biological replicates were used for the qPCR, which was repeated three times with the same results. Statistical analysis was done with twoway ANOVA $(P<0.05)$, in which genotype and seed growth media were used as the two variables, followed by Bonferroni multiple comparisons post hoc test against Col-0 on B5 media or on B5+1 $\mu \mathrm{M}$ ABA (Gutierrez et al. 2008; Rieu and Powers 2009). Primer sequences are available upon request.

\section{Results}

The Arabidopsis NF-YA Family Clusters into Five Groups of Paralogs

Phylogenetic analyses showed that the 10 members of the $N F$ $Y A$ gene family cluster into five groups of apparent paralogs: $N F-Y A 1 / N F-Y A 9, N F-Y A 2 / N F-Y A 10, N F-Y A 3 / N F-Y A 8, N F-$ $Y A 4 / N F-Y A 7$, and NF-YA5/NF-YA6 (Fig. 1a). Although the amino acid sequence of the NF-YA core domain is highly conserved, there are a few amino acids that are unique, especially in the early diverging paralogs $N F-Y A 1 / N F-Y A 9$ and $N F-Y A 2 / N F-Y A 10$ (Fig. S1). The NF-YA subunits diverge outside the core domain; however, the pairs of paralogs maintain high identity throughout the amino acid sequence (Figs. S1 and S2). The combination of highly conserved core domains and diverging, non-conserved regions suggested that studying overexpressors of the complete $N F-Y A$ gene family would potentially reveal both common and unique phenotypes.
Overexpression of $N F$-YAs Causes Severe Growth Retardation

To characterize the developmental phenotypes associated with $N F-Y A$ overexpression, qualitative and quantitative analyses were performed on two independent transgenic lines for each gene. Most NF-YA overexpression lines were shorter with smaller rosette diameters and produced fewer, smaller siliques than wild-type plants (Figs. 1b and S3). The only exceptions were $p 35 S:: N F-Y A 4$ and $p 35 S:: N F-Y A 6$, where one or both plant lines were similar to the wild type. Although most $p 35 S:: N F-Y A$ plants exhibited varying levels of dwarfism, they all went through the same developmental stages as wild-type plants with only moderate delays. Plant lines used for analysis had demonstrated accumulation of the transgenic proteins (Fig. 1c). The level of protein expressed varied with p35S::NF-YA1 and $p 35 S:: N F-Y A 4$ having the strongest expression and $p 35 S:: N F-Y A 6$ the weakest. The phenotypes seen here are in agreement with those in previous reports showing that overexpression of a smaller subset, NF-YA2, NF-YA4, NF$Y A 7$, and NF-YA10, also led to dwarf phenotypes (Liu and Howell 2010; Leyva-Gonzalez et al. 2012).

$p 35 S:: N F-Y A 5$ and $p 35 S:: N F-Y A 6$ Produce Cotyledon-Like Leaves

Two NF-YB subunits, LEAFY COTYLEDON 1 (LEC1/NFYB9) and LEC1-LIKE (L1L/NF-YB6), are essential for embryo development (West et al. 1994; Lotan et al. 1998; Kwong et al. 2003; Lee et al. 2003; Junker et al. 2012). Mutants of $L E C 1$ and $L E C 1-L$ produce cotyledons with leaflike characters (e.g., trichomes), whereas overexpressors can produce cotyledon-like leaves. Although $N F-Y B S$ required for embryo development have been identified, the presumed $N F-Y A$ and $N F-Y C$ remained unidentified. Recently, $\mathrm{Mu}$ et al. (2013) published that overexpressors of NF-YA1, NF-YA5, NF-YA6, and $N F-Y A 9$ produce cotyledon-like leaves. Examining all 10 NF-YA overexpression lines, we found that this phenotype occurs somewhat rarely and inconsistently for most lines. The exceptions were the paralogous $p 35 S:: N F-Y A 5$ and p35S::NF-YA6 lines where we consistently observed cotyledon-like leaves in the normal position of the first set of true leaves (Fig. 2a). This phenotype often persisted for multiple pairs of leaves in $p 35 S:: N F-Y A 5$ plants and ultimately precluded seed set and further characterization of $p 35 S:: N F$ YA6. In addition to gross morphological appearance resembling elongated cotyledons, leaves that should have developmentally corresponded to the first non-embryonic, true leaves were considerably smaller, had less chlorophyll, and typically lacked or had very few trichomes relative to wild-type controls (Figs. 2b and S4). The cotyledon-like leaves of $p 35 S: \because N F-Y A 5$ were further observed by differential interference contrast (DIC) microscopy and found to have vascular defects, 
Fig. 1 Characterization of $p 35 S::$

$N F-Y A$ lines. a Phylogenetic

relationship between the

Arabidopsis NF-YA genes. b

Phenotypes for two independent

lines of 3-week-old $p 35 S:: N F-Y A$

plants compared to Col- 0 . c

Protein blot for the two

independent transgenic lines of

each $p 35 S:: N F-Y A$ a
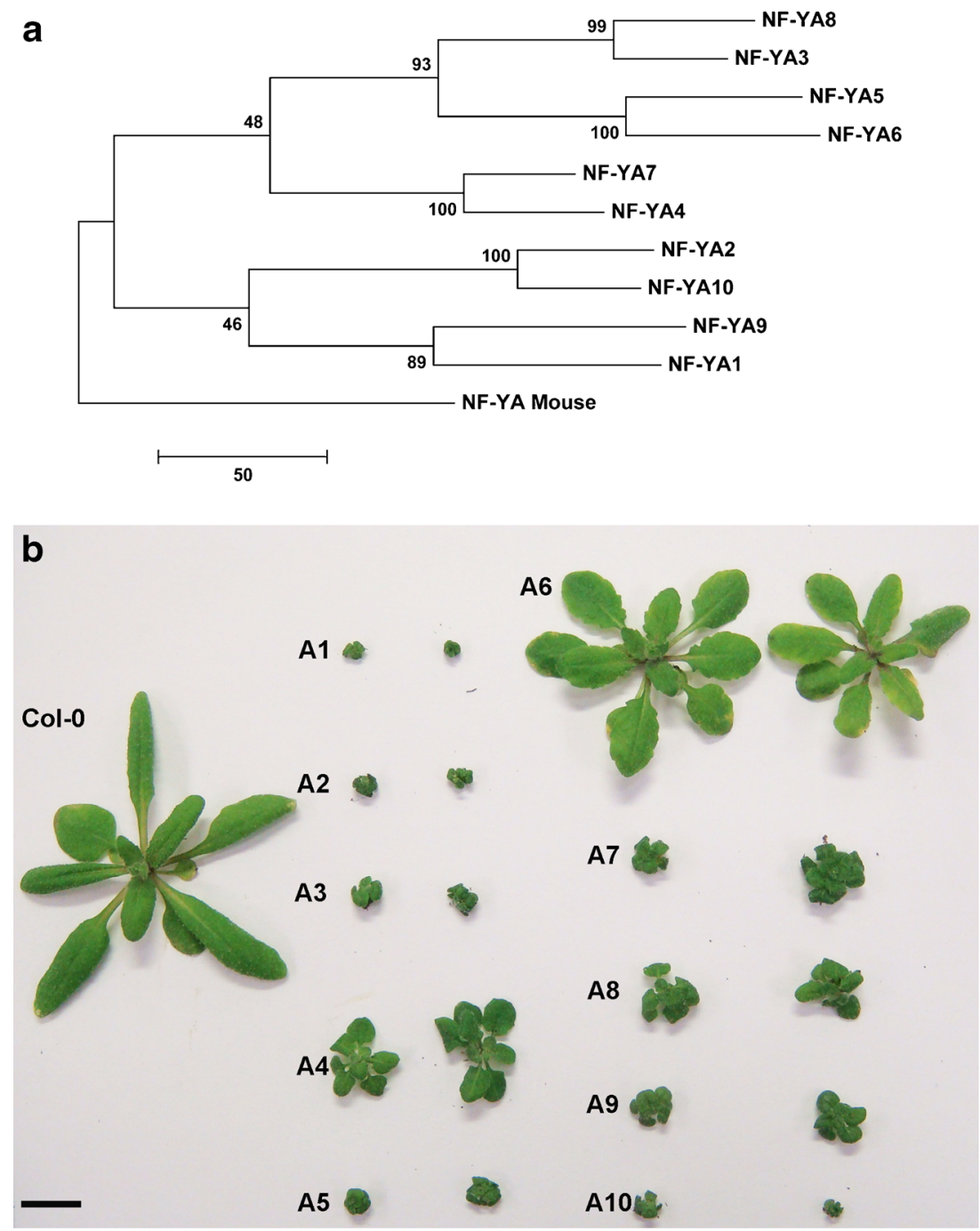

C

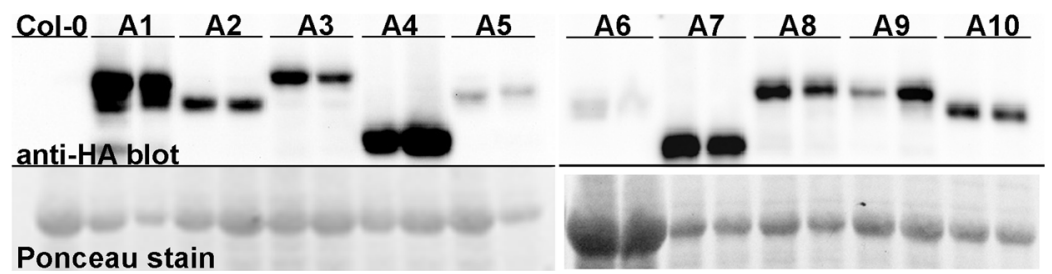

including vascular tissue that was largely limited to the midrib region (Fig. 2c). Although the $p 35 S:: N F-Y A 5$ seedlings had severe growth defects, they were tolerant to salt and osmotic stress (Fig. S5).

NF-YA Proteins Are Localized to the Nucleus

Studies in animal systems have shown that the NF-YA subunit is primarily localized to the nucleus (Frontini et al. 2004; Kahle et al. 2005). The high degree of conservation between plant and animal NF-Ys (Siefers et al. 2009) suggested that a similar localization pattern would be seen in plants. Supporting this argument, the positively charged arginine and lysine residues in the core domain of the human NF-YA subunit that are required for nuclear localization (Kahle et al. 2005) are highly conserved in Arabidopsis (Fig. S1) (Siefers et al. 2009).

Localization of all 10 NF-YA-CFP/HA proteins was studied using confocal microscopy. The CFP signal was always strongly associated with the nucleus (Fig. 3). The strength of the CFP signal corresponded well with the level of protein expression seen on the western blot (Fig. 1c). The strongest 
Fig. 2 p35S::NF-YA5 seedlings develop cotyledon-like leaves. a Seedlings of Col-0 and $p 35 S:$ : $N F-Y A 5$. b True leaves of Col-0 in comparison to cotyledon-like leaves of $p 35 S:: N F-Y A 5$. c Differential interference contrast (DIC) microscopy images of leaf venation in Col-0 and $p 35 S: \because N F$ YA5. The scale bar in a equals $1 \mathrm{~mm}$ (for Col-0) and $0.5 \mathrm{~mm}$ (for $p 35 S:: N F-Y A 5$ ) $\mathbf{b}$ equals

$2 \mathrm{~mm}$, and $\mathbf{c}$ equals $50 \mu \mathrm{m}$ a

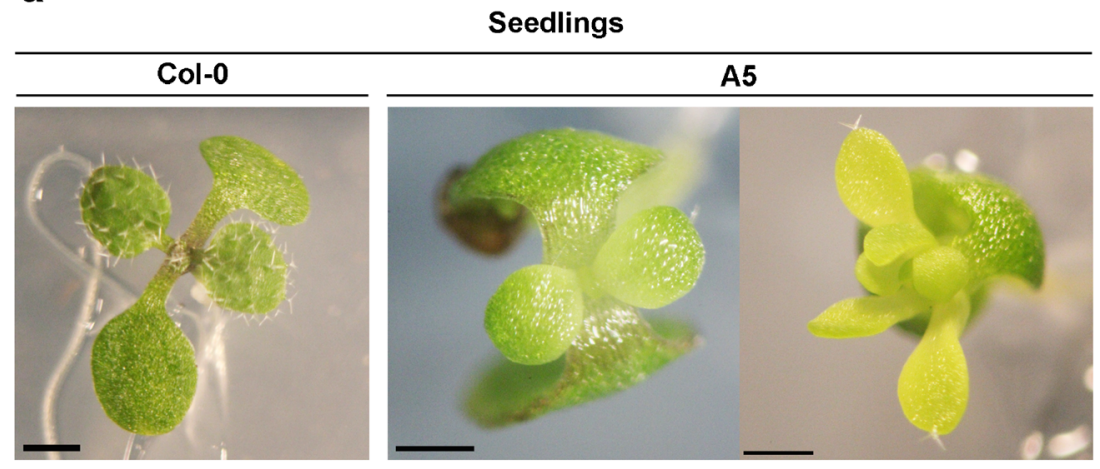

b

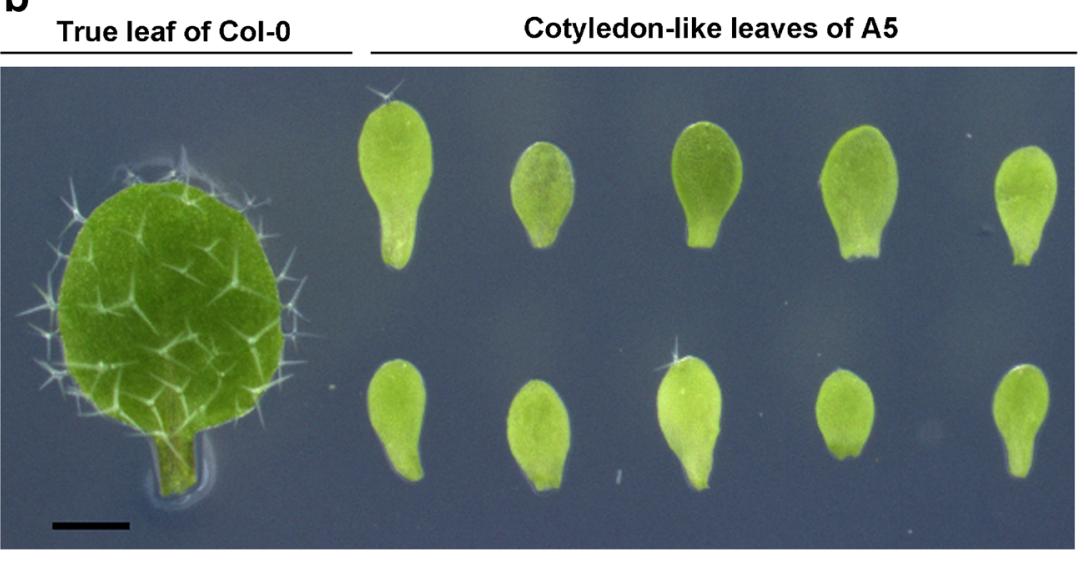

C

Leaf venation

\begin{aligned} & \hline Col-0 A5 \\ & \hline\end{aligned}

expressing lines, $p 35 S: \because N F-Y A 1$ and $p 35 S:: N F-Y A 4$, had the strongest CFP signal, whereas the weakest expressing line, $p 35 S:: N F-Y A 6$, had the weakest signal. This data supports and extends previously published data showing that Arabidopsis NF-YA1, NF-YA4, and NF-YA5 are nuclear localized (Li et al. 2008; Liu and Howell 2010; Li et al. 2013). 


\section{Col-0}

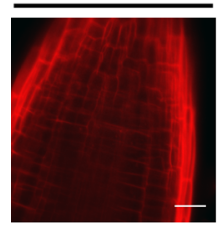

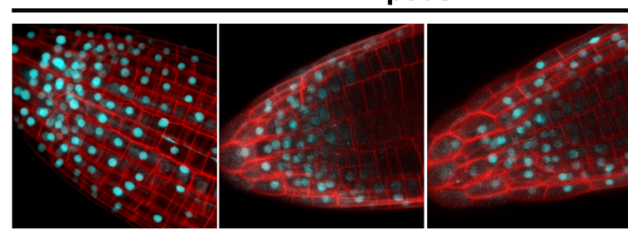

1

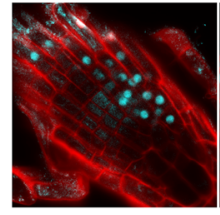

6
2

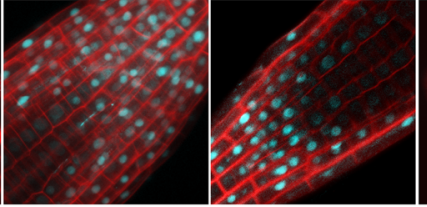

8
7
3

Fig. $3 N F-Y A$ proteins are nuclear-localized. Protein localization in Col-0 and $p 35 S:: N F-Y A-C F P / H A$ overexpression lines (numbers below pictures represent the individual NF-YA genes). The cyan fluorescence protein (CFP) signal (blue) was always strongly associated with the nucleus (note

\section{p35S::NF-YAs Have Opposing Germination Phenotypes on ABA}

NF-YC mutants can have opposing germination phenotypes on ABA (Kumimoto et al. 2013). Since the NF-Y complex binds DNA as a trimer (Sinha et al. 1996; Romier et al. 2003; Nardini et al. 2013), we reasoned that this was likely to hold true for the NF-YA and concurrently tested all 10 subunits in this study. For ease of comparison, results were graphed based on phylogenetic relationships (Fig. 1a), with the apparent closest paralogs placed on the same graph in each instance.

On non-ABA media (Gamborg's B5), most $p 35 S:: N F-Y A$ lines germinated similarly to parental Col-0, although some lines showed minor delays (Fig. 4a-e). Nevertheless, all plant lines reached $\sim 50 \%$ germination by $18-24 \mathrm{~h}$ postincubation and $\sim 100 \%$ germination by $48 \mathrm{~h}$ postincubation. On media supplemented with $1 \mu \mathrm{M}(+)-\mathrm{ABA}$, germination of parental Col-0 was delayed by approximately $72 \mathrm{~h}$. Conversely, $N F-Y A$ overexpression caused highly variable responses to ABA (Fig. 5a-e). Most interestingly, we found that overexpression of the closely related (Fig. 1a) NF-YAI and NF-YA9 genes resulted in early germination; $p 35 S:: N F-Y A 1$ lines reached $50 \%$ germination $\sim 20 \mathrm{~h}$ earlier than parental Col- 0 , while p35S::NF-YA9 lines germinated a full $48 \mathrm{~h}$ earlier (Fig. 5a). In contrast, overexpression of NF-YA2, NF-YA4, NF-YA7, NF$Y A 8$, and $N F-Y A 10$ resulted in late germination. To statistically confirm the apparent differences from parental Col-0, we performed Fisher's exact tests at $84 \mathrm{~h}$ postincubation (Fig. $5 \mathrm{f}-\mathrm{j}, 84 \mathrm{~h}$ was chosen because it is equivalent to $\sim 50 \%$ germination for Col-0 in most experiments). Additionally, we examined dose-response curves for each transgenic line using the 84 -h time point (Fig. $5 \mathrm{k}-0$ ). Collectively this data demonstrates that $N F-Y A$ overexpression consistently alters ABA responses but that $N F-Y A$ s can cause that localization was confirmed by merged images, combining the CFP localization of NF-YAs with DIC imaging and Hoechst 33342 labeling staining of the nucleus-Fig. S6). The cell walls are stained with propidium iodide (red). The scale bar in Col-0 equals $15 \mu \mathrm{m}$

opposing phenotypes in response to ABA. Additionally, we note that the ABA phenotypes are not directly correlated in any obvious way with the gross morphological data reported above (i.e., dwarf plants can give rise to both ABAsusceptible and ABA-resistant seeds, depending on the overexpressed $N F-Y A$ gene).

To see if the ABA responses of $p 35 S:: N F-Y A$ are developmentally stage dependent (i.e., if $\mathrm{ABA}$ responses extend beyond germination), the effect of ABA on root elongation was tested. Four-day-old seedlings of selected $p 35 S:: N F-Y A$ plant lines were initially grown on non-ABA media and then transferred to non-ABA (control) or ABA media $(5 \mu \mathrm{M}(+)-\mathrm{ABA})$. We selected $p 35 S:: N F-Y A 7, p 35 S: \because N F-Y A 8$, and $p 35 S:: N F-$ YA9 because they were relatively healthy (i.e., the dwarf stature was not as severe as other stable lines) and had opposing phenotypes in the germination assays (Fig. 5). On nonABA media, primary root lengths were shorter for all p35S::NF-YA lines compared to wild-type plants. Because of these differences in primary root elongation, results were graphed as the percent root elongation compared to nonABA media. The results showed that the primary root growth of all three lines was hypersensitive to ABA (Fig. S7). Thus, in contrast to the opposing germination phenotypes, all three $p 35 S:: N F-Y A$ lines showed the same negative effect of $N F-Y A$ overexpression during root growth on $\mathrm{ABA}$ media.

\section{NF-YA Genes Are Expressed in Embryos and the Endosperm}

Most of the NF-YA genes showed ABA-related germination phenotypes when overexpressed with the p35S promoter. However, a disadvantage with using overexpression constructs is that genes that do not have a biological role in a tissue may show a phenotype due to ectopic overexpression. To determine which $N F-Y A$ genes are likely to have a native biological role during seed germination, transgenic plants 
Fig. 4 Seed germination on Gamborg's B5 medium for $p 35 S:: N F-Y A$. ae Germination curves for two independent lines each of $p 35 S:: N F-Y A$ overexpressors compared to Col-0

expressing the NF-YAs fused to the GUS reporter gene and driven by their native promoter were examined (Siefers et al. 2009). This analysis showed that NF-YA1, NF-YA2, NF-YA3, $N F-Y A 4, N F-Y A 6, N F-Y A 7, N F-Y A 8$, and $N F-Y A 9$ were expressed in embryos and NF-YA1,NF-YA2,NF-YA3, NF$Y A 7$, and $N F-Y A 9$ were expressed in the endosperm (Fig. 6). The only genes that did not show expression in the embryo or the endosperm were $N F-Y A 5$ and $N F-Y A 10$. We compared these findings to publicly available expression data (Arabidopsis eFP browser, http://bar.utoronto.ca/efp/cgi-bin/efpWeb.cgi) (Winter et al. 2007) and found similar results (Fig. S8). The only significant difference was $N F-Y A 8$ where we measured fairly weak expression, but publicly available data suggested a moderately strong expression. Collectively, our data supports likely roles for most members of this gene family during seed development.

ABA-Related Genes Show Altered Expression in $p 35 S:: N F-Y A$

To further examine how NF-YA genes regulate ABA responses during seed germination, the expression of various ABA-related markers was examined. This included genes involved in ABA biosynthesis and catabolism, ABA signaling, and various downstream responses. $p 35 S:: N F-Y A 8$ and p35S::NF-YA9 were selected for qPCR analyses due to their opposing germination phenotypes ( $p 35 S:: N F-Y A 8$ is hypersensitive and $p 35 S:: N F-Y A 9$ is hyposensitive to ABA, Fig. 5a, b). $N F$-YA 8 and NF-YA9 were 100-fold and 40-fold upregulated, respectively (Fig. S9).

Initially, the expression of ABA-related markers on seeds incubated on B5 media was examined. Two members of the 9cis-epoxycarotenoid dioxygenase (NCED) gene family, NCED3 and NCED6, were misregulated in the overexpressors (Fig. 7a). These genes control the rate-limiting step of ABA biosynthesis during dormancy and seed germination (Ruggiero et al. 2004; Lefebvre et al. 2006; Frey et al. 2012). NCED3 was significantly upregulated in both $p 35 S:$ : $N F-Y A 8$ and $p 35 S:: N F-Y A 9$ seeds and NCED6 in $p 35 S: \because N F-$ $Y A 9$ seeds. Following synthesis, ABA $8^{\prime}$-hydroxylation is a key mechanism by which $\mathrm{ABA}$ is catabolized. A CYP707A gene family member that encodes ABA 8'-hydroxylases during dormancy and seed germination, CYP707A1 (Okamoto et al. 2006), was significantly downregulated in both $p 35 S:$ : $N F-Y A 8$ and $p 35 S:: N F-Y A 9$ seeds (Fig. 7b). ABA signaling components were also misregulated in the overexpressors, including the PYL6 ABA receptor, the SnRK2.6/OST1 and SnRK2.8 kinases, and the $A B I 1$ phosphatase (Fig. 7c-e). In addition, $R A B 18$, a well-known ABA response gene (Lang

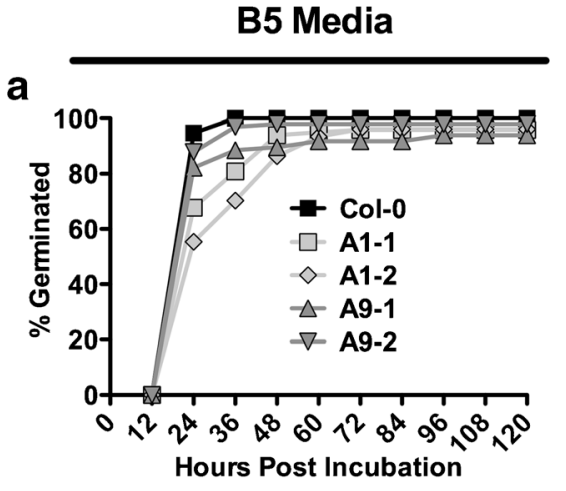

b

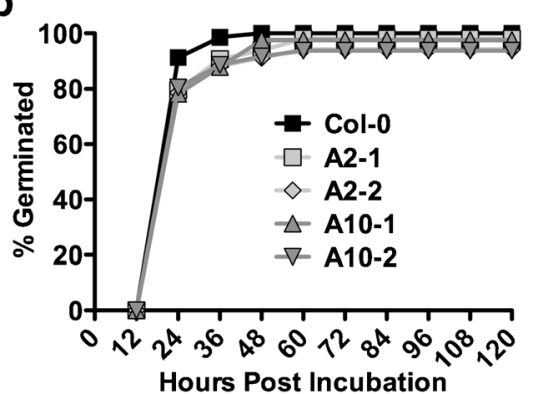

C

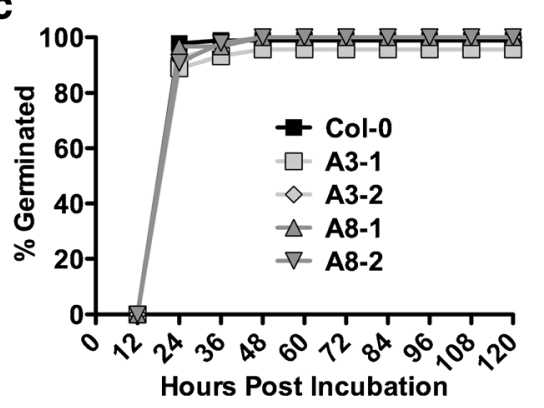

d

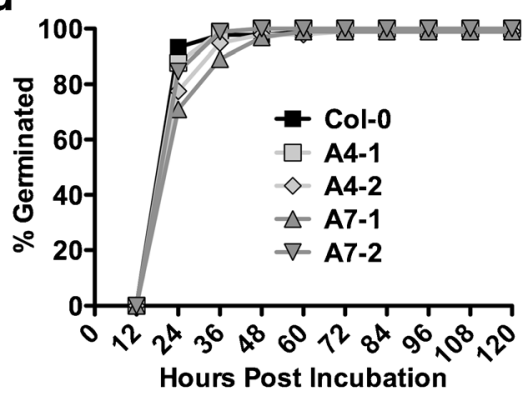

e

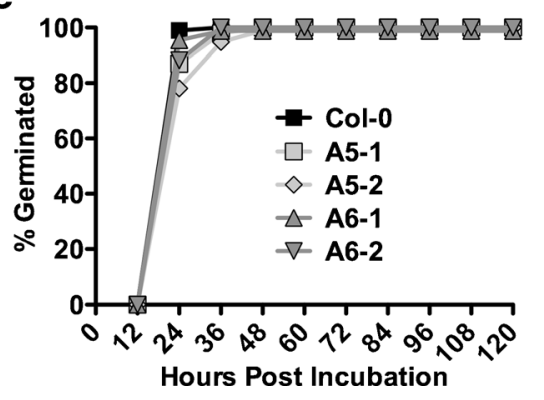



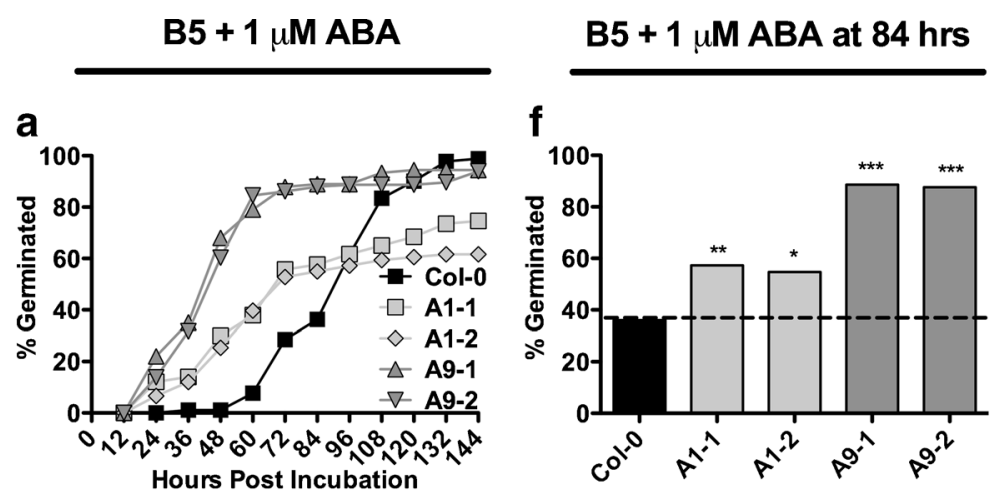

\section{Dose Response at $84 \mathrm{hrs}$}

b

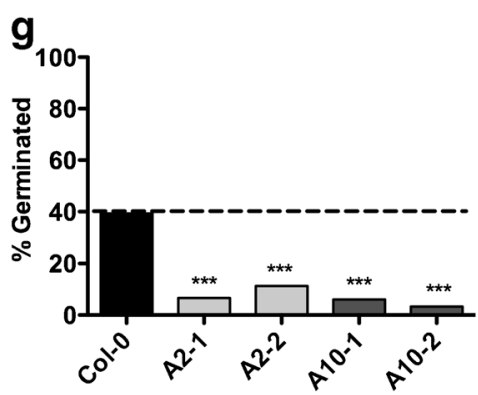

k

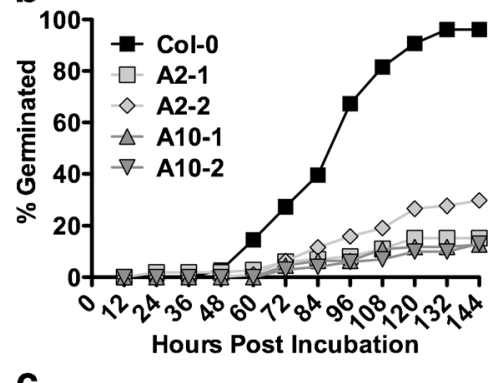

C

h
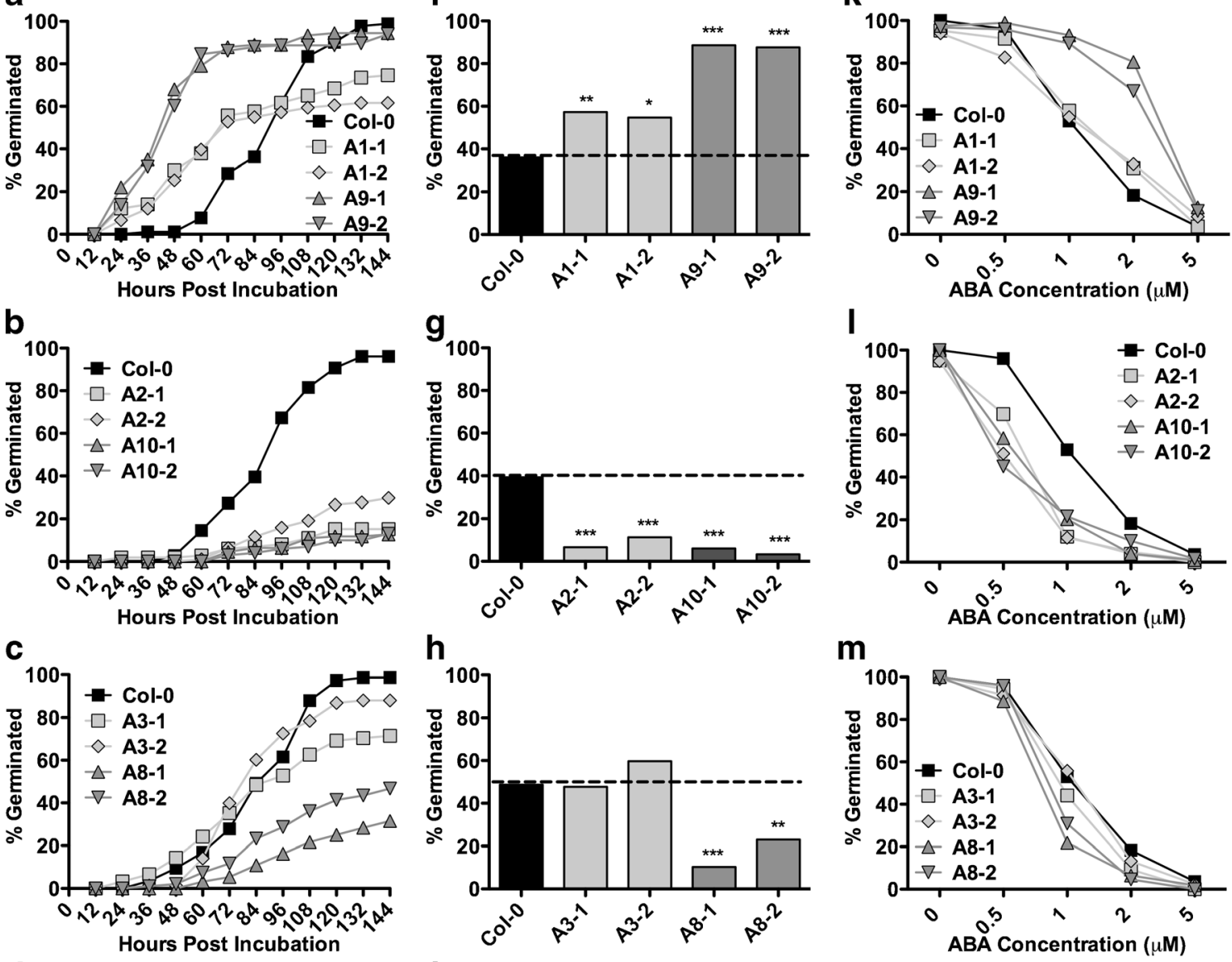

I

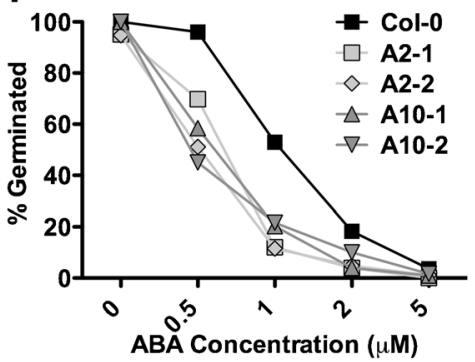

m

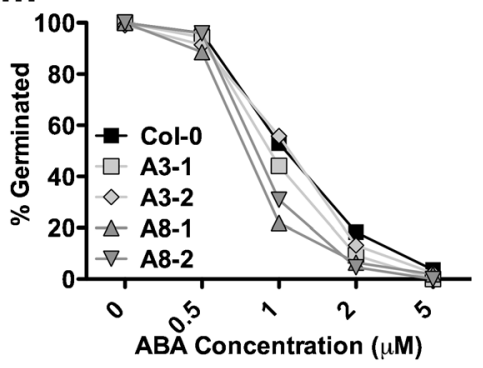

i
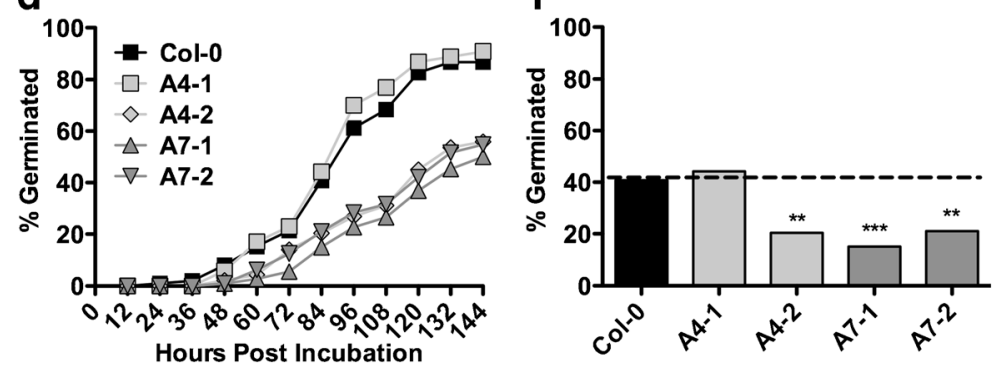

n
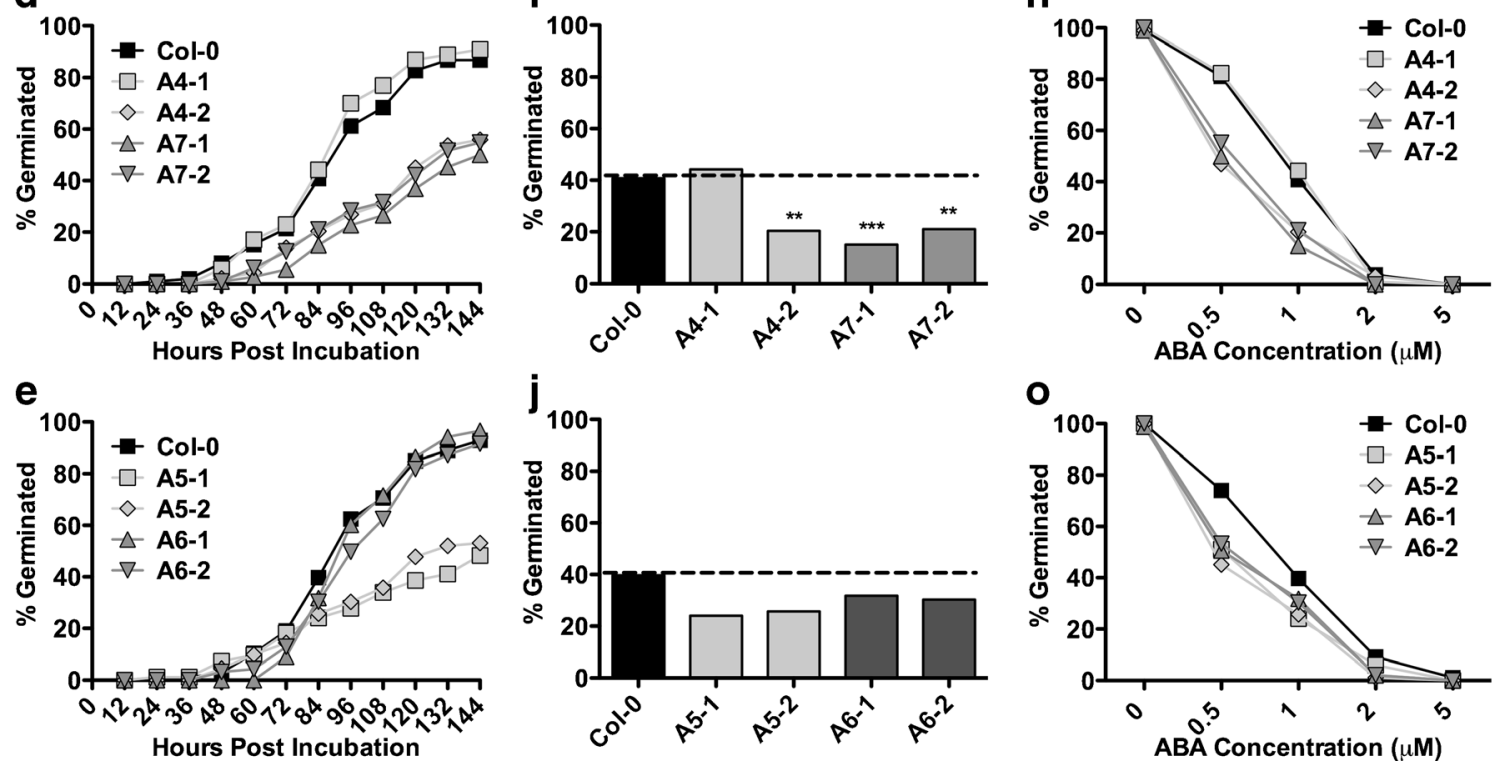

Fig. 5 p35S::NF-YA overexpressors show opposing germination phenotypes on ABA. a-e Germination curves for two independent $p 35 \mathrm{~S}: \because \mathrm{NF}$ -

$0.5,1,2$, and $5 \mu \mathrm{M} \mathrm{ABA}$ at $84 \mathrm{~h}$ postincubation. Asterisks for $\mathbf{f}$ to $\mathbf{j}$ are $Y A$ lines. $\mathbf{f}-\mathbf{j}$ Germination at $84 \mathrm{~h}$ postincubation. $\mathbf{k}-\mathbf{0}$ Dose responses on

Fisher's exact test $p$ values; ${ }^{*} p<0.01,{ }^{* *} p<0.001,{ }^{* * *} p<0.0001$

and Palva 1992), was sixfold upregulated in $p 35 S:: N F-Y A 9$ seeds (Fig. 7f).
Expression of these genes after ABA treatment was also evaluated. Strong upregulation (216-fold) of $R A B 18$ in 

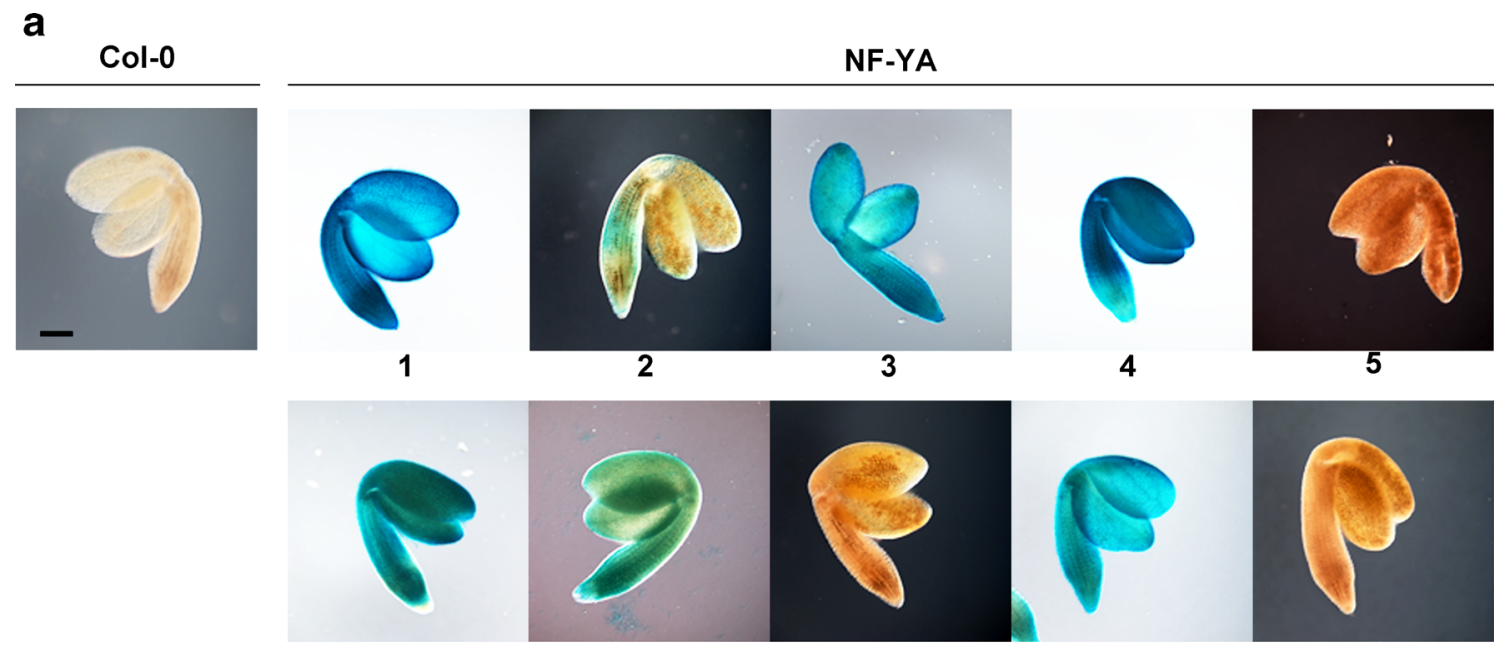

7

8

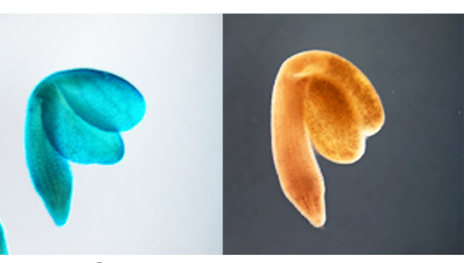

9

10
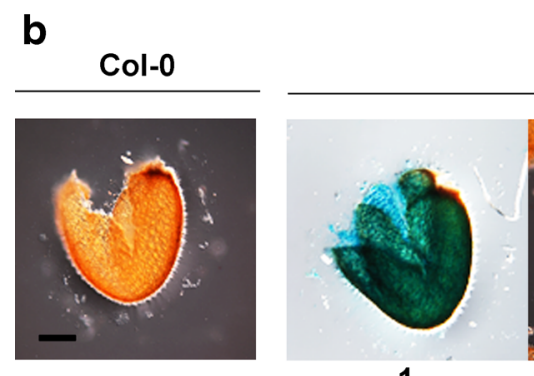

1

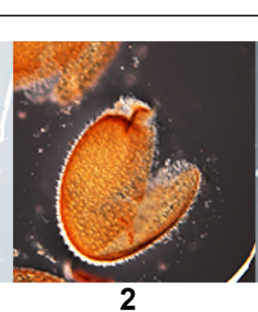

NF-YA

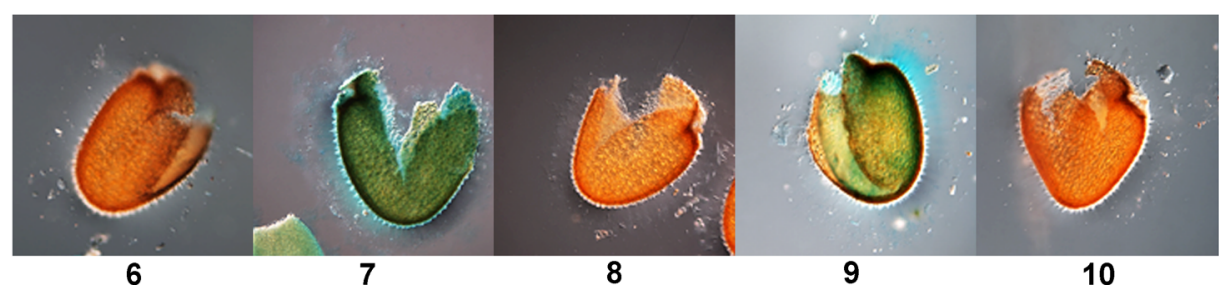

Fig. $6 \mathrm{NF}$-YA genes are expressed in the endosperm and embryos (numbers below pictures represent the individual NF-YA genes). The native expression of NF-YA genes in seeds imbibed for $24 \mathrm{~h}$ are shown for $\mathbf{a}$ embryos and $\mathbf{b}$ seed coat/endosperm. The scale bar in Col-0 equals $50 \mu \mathrm{m}$

parental Col-0 showed that the ABA treatment was successful (Fig. 7f). When the seeds where incubated on ABA, NCED3 was 40-fold upregulated in response to ABA in the wild type but only 10-fold upregulated in the overexpressors (Fig. 7a). ABA marker genes, $A B F 3, A I A$, and $H A B 1$, showed a similar trend (Fig. S10). In addition, $C Y P 707 A 1$ was significantly downregulated in $p 35 S:: N F-Y A 8$ seeds compared to the wild type (Fig. 7b) and $S n R K 2.8$ was twofold downregulated in wild type and nearly 10 -fold downregulated in the overexpressors on ABA (Fig. 7d).

\section{Discussion}

In the presence of ABA, $p 35 S:: N F-Y A$-expressing seeds can show opposing germination phenotypes. Overexpressors of $N F-Y A 1$ and NF-YA9 were hyposensitive, whereas overexpressors of $N F-Y A 2, N F-Y A 4, N F-Y A 5, N F-Y A 7, N F$ $Y A 8$, and $N F-Y A 10$ were hypersensitive to ABA. Opposing germination phenotypes were previously observed for the $N F$ $Y C$ subunits. An $n f-y c 3 n f-y c 9$ double mutant and an $n f-y c 3 n f-$ $y c 4 n f-y c 9$ triple mutant showed reduced germination inhibition in response to ABA, whereas single and double mutants with $n f-y c 4$ showed hypersensitivity to ABA (Kumimoto et al. 2013). It is important to note that in the case of $n f-y c$ observations, these were based on loss-of-function/hypomorphic mutations. Thus, opposing phenotypes are not necessarily a simple artifact of ectopic overexpression. While opposing germination phenotypes have not been published on the $N F$ $Y B$ subunits, the overexpression of two paralogs in the $N F-Y B$ family, $N F-Y B 2$ and $N F-Y B 3$, led to ABA hypersensitivity (Kumimoto et al. 2013). The presence of opposing ABA phenotypes in NF-YA and NF-YC subunits and the fact that NF-Y complexes bind DNA as a trimer (Sinha et al. 1996; 
Fig. 7 ABA response genes are misregulated in $p 35 S: \because N F-Y A 8$ and $p 35 S: \because N F-Y A 9$ seeds. Gene expression analyzed by qPCR for genes involved in ABA a biosynthesis, b catabolism, c receptors, $\mathbf{d}$ kinases, $\mathbf{e}$ phosphatases, and $\mathbf{f}$ responses. Asterisks represent significant differences derived from two-way ANOVA $(p<0.05)$, in which genotype and seed growth media are the two variables, followed by Bonferroni multiple comparisons post hoc test against Col-0 on B5 media or on $\mathrm{B} 5+1 \mu \mathrm{M}$ ABA a

Biosynthesis

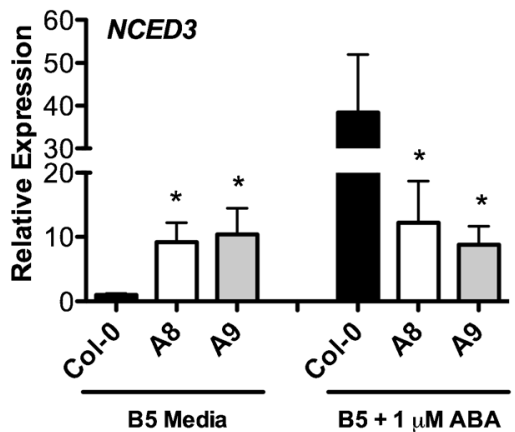

b
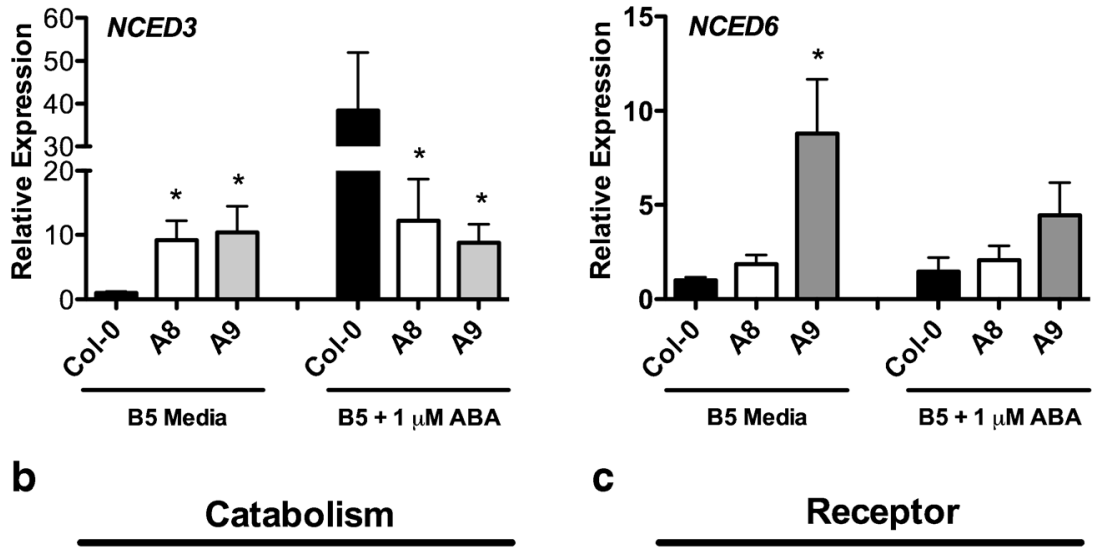

C
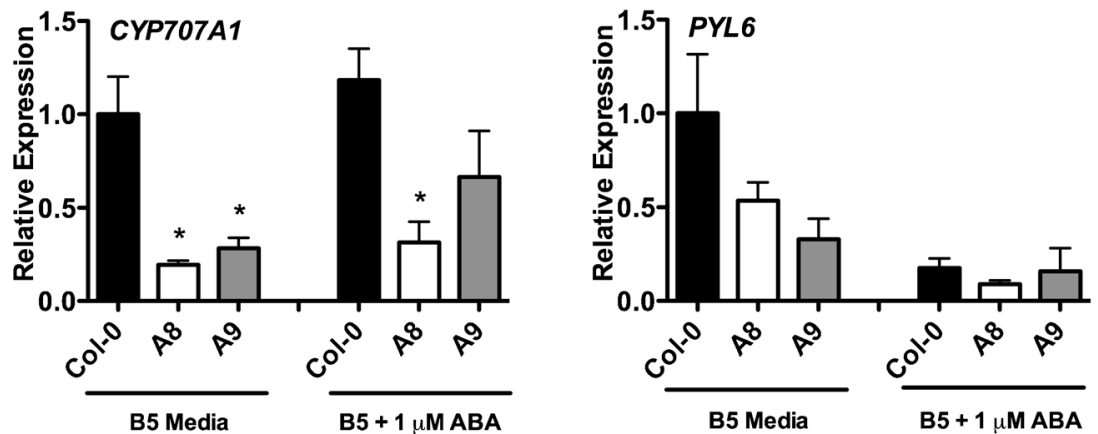

d

Kinases
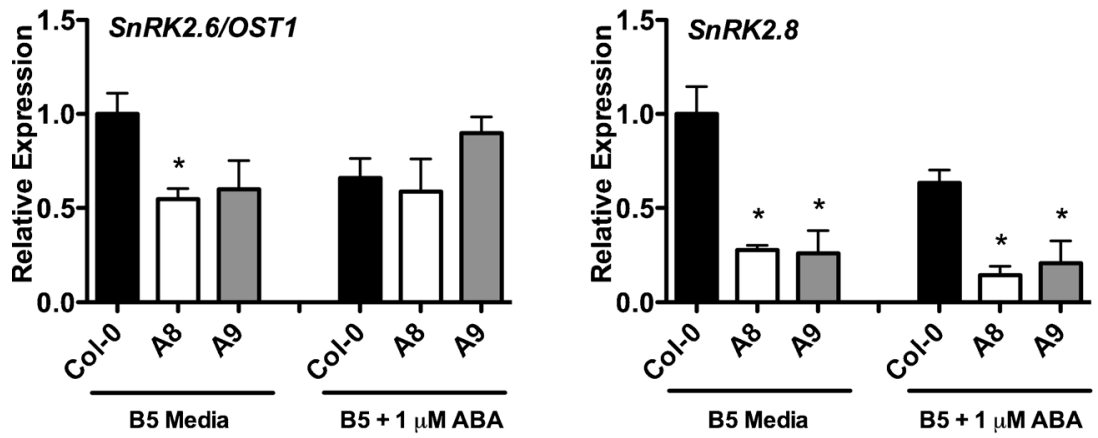

e

Phosphatase

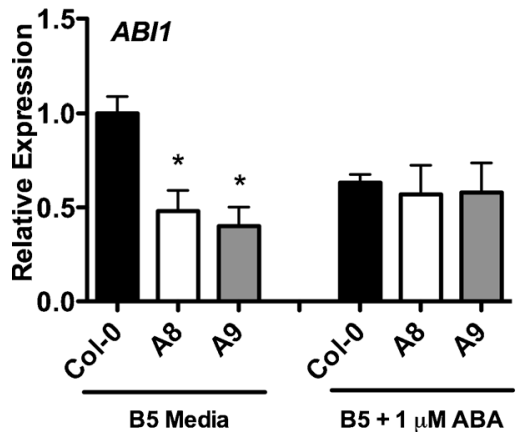

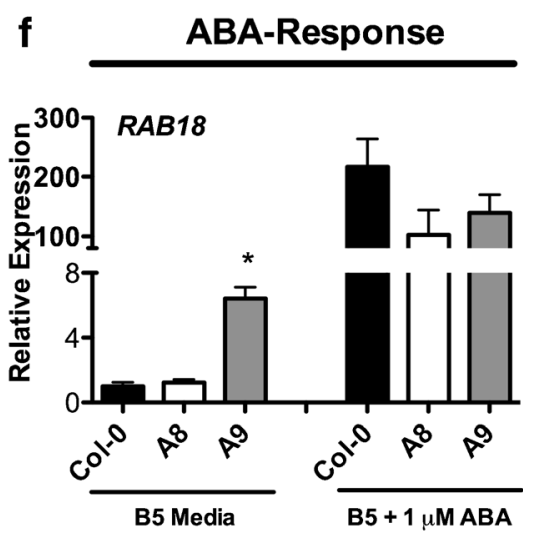


Romier et al. 2003; Nardini et al. 2013) suggests that a similar phenomenon would be expected with the $N F-Y B$ subunits. Supporting this hypothesis, preliminary data from the Holt Lab suggests that overexpression of some $N F-Y B$ s also leads to ABA hyposensitivity (BFH, unpublished data). These results indicate that while the NF-Y proteins have retained high degrees of similarity, especially in the residues necessary for NF-Y complex formation and DNA binding (Siefers et al. 2009), they may be evolving unique, even antagonistic, regulatory roles for some processes. Similar phenomena from plant transcription factor families include the auxin response factors (ARFs), which include both activators and repressors of auxin response elements (Ulmasov et al. 1999) and WRKY family members, which include both positive and negative regulators of disease resistance (Eulgem and Somssich 2007).

$N F-Y C 3$ and NF-YC9, the two NF-YC subunits with mutants hyposensitive to ABA, are paralogs whereas NF-YC4 (mutant hypersensitive to $\mathrm{ABA}$ ) is more distantly related (Siefers et al. 2009). Similarly, ABA responses for the NF$Y A$ s appear connected to their phylogenetic relationships. The two $N F-Y A$ subunits that are hyposensitive to ABA during seed germination, $N F-Y A 1$ and $N F-Y A 9$, are closely related paralogs sharing a recent common ancestor (Fig. 1a). Similarly, NF-YA2 and NF-YA10 also share a recent common ancestor and both are hypersensitive to ABA. While amino acid alignments in the conserved domains of all 10 NF-YA are highly similar, NF-YA1 and NF-YA9 do have a few unique amino acids that will provide targets for future mutational analyses towards uncovering the specific changes leading to functional differences.

Our findings of reduced ABA sensitivity in seeds overexpressing NF-YA1 and NF-YA9 are in contrast to a recent report by $\mathrm{Mu}$ et al. (2013) where they reported hypersensitivity. However, the authors appear to define germination as emerged plants after 5 days (i.e., visible cotyledons on a growth plate) - what might be more properly defined as the "greening rate" (Kim et al. 2004). Here, germination is more narrowly defined as the emergence of the radical from the seed coat (Bewley 1997). This is an important distinction as previous research suggests that these two phenotypes are not always directly correlated (Kim et al. 2004; Kumimoto et al. 2013). In fact, $n f-y c 9$ single mutants did not have a germination phenotype but showed an early greening phenotype. Further, in contrast to an ABA-hypersensitive germination phenotype, $n f-y c 4 n f-y c 9$ double mutants also had an early greening phenotype (Kumimoto et al. 2013). If the same 5-day time point is examined in isolation for the current data, it is in agreement with that reported by Mu et al. (2013) for NF-YA1 overexpression. However, this hides the fact that most of the $N F-Y A 1$ overexpressors germinate significantly faster than parental Col-0 (Fig. 5a). The day 5 (and later) measurement for NF-YAl suggests that total germination percentage never reaches $100 \%$, but, nevertheless, those that do germinate do so more quickly than Col-0. Thus, our data and previous data strongly suggest that germination and greening are separable processes that need to be carefully defined and quantified as such. Further, although $N F-Y A 9$ overexpression led to reduced ABA sensitivity during germination, the seedlings were hypersensitive to ABA during root elongation. This demonstrates that $\mathrm{ABA}$ sensitivity can vary significantly at different developmental time points. The ABRE-binding bZIP transcription factor ABF2 also shows a similar phenomenon (Kim et al. 2004). While $p 35 S:: A B F 2$ seeds germinate as wild type on $\mathrm{ABA}$, they are hypersensitive to $\mathrm{ABA}$ during root growth. In contrast, overexpressing $A B F 3$ and $A B F 4$ (members of the same subfamily) results in hypersensitivity to ABA during both seed germination and root elongation (Kang et al. 2002).

It is possible that the NF-Y both physically interacts with and regulates the expression of genes that mediate seed germination in response to ABA. In the case of physical interactions, it was shown that NF-YB and NF-YC subunits physically interact with transcription factors that mediate ABA responses, including ABFs, HY5, and bZIP67 (Yamamoto et al. 2009; Kumimoto et al. 2013). In the current study, NCED 3 and NCED6, genes that regulate the rate-limiting step of ABA biosynthesis during germination (Ruggiero et al. 2004; Lefebvre et al. 2006; Frey et al. 2012), were upregulated and CYP707A1, a gene that regulates ABA catabolism during germination (Okamoto et al. 2006), was downregulated. It is possible that NF-YA regulates the level of ABA during germination and that the overexpression of NF-YA genes led to higher levels of ABA in seeds due to increased production and decreased breakdown. In addition to genes that regulate $\mathrm{ABA}$ biosynthesis and catabolism, genes that regulate $\mathrm{ABA}$ signaling were downregulated. The downregulation of $\mathrm{ABA}$ signaling genes is consistent with a previous publication, which showed similar results with NF-YA2, NF-YA3, NF$Y A 7$, and $N F-Y A 10$ overexpressors (Leyva-Gonzalez et al. 2012). This shows that most members of the $N F-Y A$ family are able to regulate ABA signaling components during germination and other ABA-mediated developmental responses. In addition to misregulation of ABA-related markers, ABAinduced genes showed attenuated response to $\mathrm{ABA}$ application. Similarly, ABA induction of known ABA-induced genes was reduced or eliminated in the pyr 1 pyll pyl2 pyl4 pyl5 pyls sextuple mutant (Gonzalez-Guzman et al. 2012) and the snrk2.2 snrk2.3 snrk2.6 triple mutant (Fujii and Zhu 2009; Fujita et al. 2009; Nakashima et al. 2009). The current study and Leyva-Gonzalez et al. (2012) have shown the downregulation of ABA receptors and kinases in NF-YA overexpressors. It is possible that the reduced induction of ABA-regulated genes in the NF-YA overexpressors is partly due to the downregulation of the receptors and kinases. Although this study identified opposing ABA phenotypes in the NF-YA family 
during germination, the qPCR analysis did not identify opposingly regulated genes. A high-throughput analysis using microarray or RNA-seq techniques that identifies global changes in gene expression may be required to identify the genes that lead to the opposing germination phenotypes.

Our finding that $p 35 S:: N F-Y A 5$ is resistant to abiotic stress is in agreement with that of $\mathrm{Li}$ et al. (2008) where the authors demonstrate that NF-YA5 overexpressors are drought tolerant. The authors found that NF-YA5 transcript was strongly induced by drought conditions. A miRNA, miR169, which targets the NF-YA5 transcript, was downregulated during drought conditions and ABA treatment, and this decrease in miR169 was partially responsible for the increase in NF-YA5 transcript accumulation. Similar examples are seen in plant species such as Medicago truncatula, soybean (Glycine max), and aspen (Populus tremuloides), where miR169 is demonstrated to regulate $N F-Y A$ transcripts during diverse development programs such as nodulation, drought responses, and vegetative bud formation (Combier et al. 2006; Ni et al. 2013; Potkar et al. 2013). Because most NF-YA genes are predicted targets of miR169 (Rhoades et al. 2002), their role in ABA-mediated germination and embryo development needs further investigation.

Members of the NF-Y gene family, common to all eukaryotes, have undergone a large expansion in the plant kingdom; however, the significance of this expansion is not well understood. The same $N F-Y C$ family members that have opposing roles during germination actually work together to regulate flowering time (Kumimoto et al. 2010, 2013), demonstrating both unique and overlapping roles for NF-Y during plant development. The current study adds to the growing evidence for both unique and overlapping roles for the $N F-Y$ in the plant lineage by identifying the opposing role for the $N F-Y A$ family during germination. It is important to note that studying the complete gene family aided in identifying the opposing roles for this genes family. Future studies of $N F-Y A$ family roles during development can potentially identify similar unique and overlapping responses and may eventually help explain the evolutionary advantages for the expansion of the plant $N F-Y \mathrm{~s}$.

Acknowledgments The authors thank Dr. Bing Zhang, Dr. Ben Smith, and Taylor Fore for the usage and assistance given with the Zeiss Axiolmager.Z1/ApoTome microscope and Leica TCS SP8 confocal laser scanning microscope and Conner Boatright and Zach Myers for the technical support.

Open Access This article is distributed under the terms of the Creative Commons Attribution License which permits any use, distribution, and reproduction in any medium, provided the original author(s) and the source are credited.

\section{References}

Ballif J, Endo S, Kotani M, MacAdam J, Wu Y (2011) Over-expression of HAP3b enhances primary root elongation in Arabidopsis. Plant Physiol Biochem: PPB/Societe francaise de physiologie vegetale 49(6):579-583

Ben-Naim O, Eshed R, Parnis A, Teper-Bamnolker P, Shalit A, Coupland G, Samach A, Lifschitz E (2006) The CCAAT binding factor can mediate interactions between CONSTANS-like proteins and DNA. The Plant Journal 46(3):462-476

Bewley D (1997) Seed germination and dormancy. Plant Cell 9:1055-1066

Cai X, Ballif J, Endo S, Davis E, Liang M, Chen D, DeWald D, Kreps J, Zhu T, Wu Y (2007) A putative CCAAT-binding transcription factor is a regulator of flowering timing in Arabidopsis. Plant Physiol 145(1):98-105

Cao S, Kumimoto RW, Siriwardana CL, Risinger JR, Holt BF III (2011) Identification and characterization of $N F-Y$ transcription factor families in the monocot model plant Brachypodium distachyon. PLoS One 6(6):e21805

Chen NZ, Zhang XQ, Wei PC, Chen QJ, Ren F, Chen J, Wang XC (2007) AtHAP $3 b$ plays a crucial role in the regulation of flowering time in Arabidopsis during osmotic stress. J Biochem Mol Biol 40(6):10831089

Choi HI, Park HJ, Park JH, Kim S, Im MY, Seo HH, Kim YW, Hwang I, Kim SY (2005) Arabidopsis calcium-dependent protein kinase AtCPK32 interacts with ABF4, a transcriptional regulator of abscisic acid-responsive gene expression, and modulates its activity. Plant Physiol 139(4):1750-1761

Clough SJ, Bent AF (1998) Floral dip: a simplified method for Agrobacterium-mediated transformation of Arabidopsis thaliana. Plant J 16(6):735-743

Combier JP, de Billy F, Gamas P, Niebel A, Rivas S (2008) Transregulation of the expression of the transcription factor MtHAP2-1 by a uORF controls root nodule development. Genes Dev 22(11): $1549-1559$

Combier JP, Frugier F, de Billy F, Boualem A, El-Yahyaoui F, Moreau S, Vernie T, Ott T, Gamas P, Crespi M, Niebel A (2006) MtHAP2-1 is a key transcriptional regulator of symbiotic nodule development regulated by microRNA169 in Medicago truncatula. Genes Dev 20(22):3084-3088

Czechowski T, Stitt M, Altmann T, Udvardi MK, Scheible WR (2005) Genome-wide identification and testing of superior reference genes for transcript normalization in Arabidopsis. Plant Physiol 139(1):517

Dolfini D, Gatta R, Mantovani R (2012) $N F-Y$ and the transcriptional activation of CCAAT promoters. Crit Rev Biochem Mol Biol 47(1): 29-49

Earley KW, Haag JR, Pontes O, Opper K, Juehne T, Song K, Pikaard CS (2006) Gateway-compatible vectors for plant functional genomics and proteomics. Plant J 45:616-629

Eulgem T, Somssich IE (2007) Networks of WRKY transcription factors in defense signaling. Curr Opin Plant Biol 10(4):366-371

Felsenstein J (1985) Confidence-limits on phylogenies - an approach using the bootstrap. Evolution 39(4):783-791

Finkelstein R, Gampala SS, Lynch TJ, Thomas TL, Rock CD (2005) Redundant and distinct functions of the ABA response loci ABAINSENSITIVE(ABI)5 and ABRE-BINDING FACTOR (ABF)3. Plant Mol Biol 59(2):253-267

Frey A, Effroy D, Lefebvre V, Seo M, Perreau F, Berger A, Sechet J, To A, North HM, Marion-Poll A (2012) Epoxycarotenoid cleavage by NCED5 fine-tunes ABA accumulation and affects seed dormancy and drought tolerance with other NCED family members. Plant J 70(3):501-512

Frontini M, Imbriano C, Manni I, Mantovani R (2004) Cell cycle regulation of $N F-Y C$ nuclear localization. Cell Cycle 3(2):217-222 
Fujii H, Chinnusamy V, Rodrigues A, Rubio S, Antoni R, Park SY, Cutler SR, Sheen J, Rodriguez PL, Zhu JK (2009) In vitro reconstitution of an abscisic acid signalling pathway. Nature 462(7273):660-664

Fujii H, Zhu JK (2009) Arabidopsis mutant deficient in 3 abscisic acidactivated protein kinases reveals critical roles in growth, reproduction, and stress. Proc Natl Acad Sci U S A 106(20):8380-8385

Fujita Y, Nakashima K, Yoshida T, Katagiri T, Kidokoro S, Kanamori N, Umezawa T, Fujita M, Maruyama K, Ishiyama K, Kobayashi M, Nakasone S, Yamada K, Ito T, Shinozaki K, Yamaguchi-Shinozaki K (2009) Three SnRK2 protein kinases are the main positive regulators of abscisic acid signaling in response to water stress in Arabidopsis. Plant Cell Physiol 50(12):2123-2132

Furihata T, Maruyama K, Fujita Y, Umezawa T, Yoshida R, Shinozaki K, Yamaguchi-Shinozaki K (2006) Abscisic acid-dependent multisite phosphorylation regulates the activity of a transcription activator AREB1. Proc Natl Acad Sci U S A 103(6):1988-1993

Gonzalez-Guzman M, Pizzio GA, Antoni R, Vera-Sirera F, Merilo E, Bassel GW, Fernandez MA, Holdsworth MJ, Perez-Amador MA, Kollist H, Rodriguez PL (2012) Arabidopsis PYR/PYL/RCAR receptors play a major role in quantitative regulation of stomatal aperture and transcriptional response to abscisic acid. Plant Cell 24(6):2483-2496

Gosti F, Beaudoin N, Serizet C, Webb AA, Vartanian N, Giraudat J (1999) ABI1 protein phosphatase $2 \mathrm{C}$ is a negative regulator of abscisic acid signaling. Plant Cell 11(10):1897-1910

Gusmaroli G, Tonelli C, Mantovani R (2001) Regulation of the CCAATBinding NF-Y subunits in Arabidopsis thaliana. Gene 264(2):173-185

Gusmaroli G, Tonelli C, Mantovani R (2002) Regulation of novel members of the Arabidopsis thaliana CCAAT-binding nuclear factor $\mathrm{Y}$ subunits. Gene 283(1-2):41-48

Gutierrez L, Mauriat M, Pelloux J, Bellini C, Van Wuytswinkel O (2008) Towards a systematic validation of references in real-time RT-PCR. Plant Cell 20(7):1734-1735

Huala E, Dickerman AW, Garcia-Hernandez M, Weems D, Reiser L, LaFond F, Hanley D, Kiphart D, Zhuang M, Huang W, Mueller LA, Bhattacharyya D, Bhaya D, Sobral BW, Beavis W, Meinke DW, Town CD, Somerville C, Rhee SY (2001) The Arabidopsis Information Resource (TAIR): a comprehensive database and webbased information retrieval, analysis, and visualization system for a model plant. Nucleic Acids Res 29(1):102-105

Junker A, Monke G, Rutten T, Keilwagen J, Seifert M, Thi TM, Renou JP, Balzergue S, Viehover P, Hahnel U, Ludwig-Muller J, Altschmied L, Conrad U, Weisshaar B, Baumlein H (2012) Elongation-related functions of LEAFY COTYLEDON1 during the development of Arabidopsis thaliana. Plant J 71(3):427-442

Kahle J, Baake M, Doenecke D, Albig W (2005) Subunits of the heterotrimeric transcription factor $N F-Y$ are imported into the nucleus by distinct pathways involving importin beta and importin 13 . Mol Cell Biol 25(13):5339-5354

Kang JY, Choi HI, Im MY, Kim SY (2002) Arabidopsis basic leucine zipper proteins that mediate stress-responsive abscisic acid signaling. Plant Cell 14(2):343-357

Kay R, Chan A, Daly M, McPherson J (1987) Duplication of CaMV 35S promoter sequences creates a strong enhancer for plant genes. Science 236(4806): 1299-1302

Kim S, Kang JY, Cho DI, Park JH, Kim SY (2004) ABF2, an ABREbinding bZIP factor, is an essential component of glucose signaling and its overexpression affects multiple stress tolerance. Plant $\mathrm{J}$ 40(1):75-87

Kumimoto RW, Adam L, Hymus GJ, Repetti PP, Reuber TL, Marion CM, Hempel FD, Ratcliffe OJ (2008) The Nuclear Factor Y subunits $N F-Y B 2$ and $N F-Y B 3$ play additive roles in the promotion of flowering by inductive long-day photoperiods in Arabidopsis. Planta 228(5):709-723

Kumimoto RW, Siriwardana CL, Gayler KK, Risinger JR, Siefers N, Holt BF III (2013) NUCLEAR FACTOR Y transcription factors have both opposing and additive roles in ABA-mediated seed germination. PLoS One 8(3):e59481

Kumimoto RW, Zhang Y, Siefers N, Holt BF III (2010) NF-YC3, NF-YC4 and $N F-Y C 9$ are required for CONSTANS-mediated, photoperioddependent flowering in Arabidopsis thaliana. Plant J 63:379-391

Kusnetsov V, Landsberger M, Meurer J, Oelmuller R (1999) The assembly of the CAAT-box binding complex at a photosynthesis gene promoter is regulated by light, cytokinin, and the stage of the plastids. J Biol Chem 274(50):36009-36014

Kwong RW, Bui AQ, Lee H, Kwong LW, Fischer RL, Goldberg RB, Harada JJ (2003) LEAFY COTYLEDON1-LIKE defines a class of regulators essential for embryo development. Plant Cell 15(1):5-18

Laloum T, De Mita S, Gamas P, Baudin M, Niebel A (2013) CCAAT-box binding transcription factors in plants: Y so many? Trends Plant Sci 18(3):157-166

Lang V, Palva ET (1992) The expression of a rab-related gene, rab18, is induced by abscisic acid during the cold acclimation process of Arabidopsis thaliana (L.) Heynh. Plant Mol Biol 20(5):951-962

Lee H, Fischer RL, Goldberg RB, Harada JJ (2003) Arabidopsis LEAFY COTYLEDON1 represents a functionally specialized subunit of the CCAAT binding transcription factor. Proc Natl Acad Sci U S A 100(4):2152-2156

Lefebvre V, North H, Frey A, Sotta B, Seo M, Okamoto M, Nambara E, Marion-Poll A (2006) Functional analysis of Arabidopsis NCED6 and NCED9 genes indicates that ABA synthesized in the endosperm is involved in the induction of seed dormancy. Plant J 45(3):309-319

Leyva-Gonzalez MA, Ibarra-Laclette E, Cruz-Ramirez A, HerreraEstrella L (2012) Functional and transcriptome analysis reveals an acclimatization strategy for abiotic stress tolerance mediated by Arabidopsis NF-YA family members. PLoS One 7(10):e48138

Li WX, Oono Y, Zhu J, He XJ, Wu JM, Iida K, Lu XY, Cui X, Jin H, Zhu JK (2008) The Arabidopsis NFYA5 transcription factor is regulated transcriptionally and posttranscriptionally to promote drought resistance. Plant Cell 20(8):2238-2251

Li YJ, Fang Y, Fu YR, Huang JG, Wu CA, Zheng CC (2013) NFYA1 is involved in regulation of postgermination growth arrest under salt stress in Arabidopsis. PLoS One 8(4):e61289

Liu JX, Howell SH (2010) bZIP28 and NF-Y transcription factors are activated by ER stress and assemble into a transcriptional complex to regulate stress response genes in Arabidopsis. Plant Cell 22(3): 782-796

Lotan T, Ohto M, Yee KM, West MA, Lo R, Kwong RW, Yamagishi K, Fischer RL, Goldberg RB, Harada JJ (1998) Arabidopsis LEAFY COTYLEDON1 is sufficient to induce embryo development in vegetative cells. Cell 93(7):1195-1205

Ma Y, Szostkiewicz I, Korte A, Moes D, Yang Y, Christmann A, Grill E (2009) Regulators of PP2C phosphatase activity function as abscisic acid sensors. Science 324(5930):1064-1068

Maity SN, Sinha S, Ruteshouser EC, de Crombrugghe B (1992) Three different polypeptides are necessary for DNA binding of the mammalian heteromeric CCAAT binding factor. J Biol Chem 267(23): $16574-16580$

Manni I, Caretti G, Artuso S, Gurtner A, Emiliozzi V, Sacchi A, Mantovani R, Piaggio G (2008) Posttranslational regulation of $N F-Y A$ modulates $N F-Y$ transcriptional activity. Mol Biol Cell 19(12):5203-5213

Meinke D, Muralla R, Sweeney C, Dickerman A (2008) Identifying essential genes in Arabidopsis thaliana. Trends Plant Sci 13(9): 483-491

Melcher K, Ng LM, Zhou XE, Soon FF, Xu Y, Suino-Powell KM, Park SY, Weiner JJ, Fujii H, Chinnusamy V, Kovach A, Li J, Wang Y, Li J, Peterson FC, Jensen DR, Yong EL, Volkman BF, Cutler SR, Zhu JK, Xu HE (2009) A gate-latch-lock mechanism for hormone signalling by abscisic acid receptors. Nature 462(7273):602-608

Merlot S, Gosti F, Guerrier D, Vavasseur A, Giraudat J (2001) The ABI1 and $\mathrm{ABI} 2$ protein phosphatases $2 \mathrm{C}$ act in a negative feedback 
regulatory loop of the abscisic acid signalling pathway. Plant $\mathrm{J}$ 25(3):295-303

Miyazono K, Miyakawa T, Sawano Y, Kubota K, Kang HJ, Asano A, Miyauchi Y, Takahashi M, Zhi Y, Fujita Y, Yoshida T, Kodaira KS, Yamaguchi-Shinozaki K, Tanokura M (2009) Structural basis of abscisic acid signalling. Nature 462(7273):609-614

Mu J, Tan H, Hong S, Liang Y, Zuo J (2013) Arabidopsis transcription factor genes $N F-Y A 1,5,6$, and 9 play redundant roles in male gametogenesis, embryogenesis, and seed development. Mol Plant 6(1):188-201

Nakashima K, Fujita Y, Kanamori N, Katagiri T, Umezawa T, Kidokoro S, Maruyama K, Yoshida T, Ishiyama K, Kobayashi M, Shinozaki K, Yamaguchi-Shinozaki K (2009) Three Arabidopsis SnRK2 protein kinases, SRK2D/SnRK2.2, SRK2E/SnRK2.6/OST1 and SRK2I/SnRK2.3, involved in ABA signaling are essential for the control of seed development and dormancy. Plant Cell Physiol 50(7):1345-1363

Nardini M, Gnesutta N, Donati G, Gatta R, Forni C, Fossati A, Vonrhein C, Moras D, Romier C, Bolognesi M, Mantovani R (2013) Sequence-specific transcription factor $N F-Y$ displays histone-like DNA binding and H2B-like ubiquitination. Cell 152(1-2):132-143

Nei MKS (2000) Molecular evolution and phylogenetics. Oxford University Press, New York

Nelson DE, Repetti PP, Adams TR, Creelman RA, Wu J, Warner DC, Anstrom DC, Bensen RJ, Castiglioni PP, Donnarummo MG, Hinchey BS, Kumimoto RW, Maszle DR, Canales RD, Krolikowski KA, Dotson SB, Gutterson N, Ratcliffe OJ, Heard JE (2007) Plant nuclear factor Y $(N F-Y)$ B subunits confer drought tolerance and lead to improved corn yields on water-limited acres. Proc Natl Acad Sci U S A 104(42):16450-16455

Ni Z, Hu Z, Jiang Q, Zhang H (2013) GmNFYA3, a target gene of miR169, is a positive regulator of plant tolerance to drought stress. Plant Mol Biol 82(1-2):113-129

Nishimura N, Hitomi K, Arvai AS, Rambo RP, Hitomi C, Cutler SR, Schroeder JI, Getzoff ED (2009) Structural mechanism of abscisic acid binding and signaling by dimeric PYR1. Science 326(5958): 1373-1379

Okamoto M, Kuwahara A, Seo M, Kushiro T, Asami T, Hirai N, Kamiya Y, Koshiba T, Nambara E (2006) CYP707A1 and CYP707A2, which encode abscisic acid 8'-hydroxylases, are indispensable for proper control of seed dormancy and germination in Arabidopsis. Plant Physiol 141(1):97-107

Olesen JT, Guarente L (1990) The HAP2 subunit of yeast CCAAT transcriptional activator contains adjacent domains for subunit association and DNA recognition: model for the HAP2/3/4 complex. Genes Dev 4(10):1714-1729

Pagnussat GC, Yu HJ, Ngo QA, Rajani S, Mayalagu S, Johnson CS, Capron A, Xie LF, Ye D, Sundaresan V (2005) Genetic and molecular identification of genes required for female gametophyte development and function in Arabidopsis. Development 132(3):603-614

Park SY, Fung P, Nishimura N, Jensen DR, Fujii H, Zhao Y, Lumba S, Santiago J, Rodrigues A, Chow TF, Alfred SE, Bonetta D, Finkelstein R, Provart NJ, Desveaux D, Rodriguez PL, McCourt P, Zhu JK, Schroeder JI, Volkman BF, Cutler SR (2009) Abscisic acid inhibits type $2 \mathrm{C}$ protein phosphatases via the PYR/PYL family of START proteins. Science 324(5930):10681071

Perry SE, Wang H (2003) Rapid isolation of Arabidopsis thaliana developing embryos. Bio Tech 35(2):278-280, 282

Petroni K, Kumimoto RW, Gnesutta N, Calvenzani V, Fornari M, Tonelli C, Holt BF III, Mantovani R (2012) The promiscuous life of plant NUCLEAR FACTOR Y transcription factors. Plant Cell 24(12): 4777-4792

Potkar R, Recla J, Busov V (2013) ptr-MIR169 is a posttranscriptional repressor of PtrHAP2 during vegetative bud dormancy period of aspen (Populus tremuloides) trees. Biochem Biophys Res Commun 431(3):512-518

Rhoades MW, Reinhart BJ, Lim LP, Burge CB, Bartel B, Bartel DP (2002) Prediction of plant microRNA targets. Cell 110(4):513-520

Rieu I, Powers SJ (2009) Real-time quantitative RT-PCR: design, calculations, and statistics. Plant Cell 21(4):1031-1033

Romier C, Cocchiarella F, Mantovani R, Moras D (2003) The NF-YB/ $N F-Y C$ structure gives insight into DNA binding and transcription regulation by CCAAT factor $N F-Y$. J Biol Chem 278(2):13361345

Rubio S, Rodrigues A, Saez A, Dizon MB, Galle A, Kim TH, Santiago J, Flexas J, Schroeder JI, Rodriguez PL (2009) Triple loss of function of protein phosphatases type $2 \mathrm{C}$ leads to partial constitutive response to endogenous abscisic acid. Plant Physiol 150(3):13451355

Ruggiero B, Koiwa H, Manabe Y, Quist TM, Inan G, Saccardo F, Joly RJ, Hasegawa PM, Bressan RA, Maggio A (2004) Uncoupling the effects of abscisic acid on plant growth and water relations. Analysis of sto1/nced3, an abscisic aciddeficient but salt stress-tolerant mutant in Arabidopsis. Plant Physiol 136(2):3134-3147

Saez A, Apostolova N, Gonzalez-Guzman M, Gonzalez-Garcia MP, Nicolas C, Lorenzo O, Rodriguez PL (2004) Gain-of-function and loss-of-function phenotypes of the protein phosphatase $2 \mathrm{C}$ HAB1 reveal its role as a negative regulator of abscisic acid signalling. Plant J 37(3):354-369

Santiago J, Dupeux F, Round A, Antoni R, Park SY, Jamin M, Cutler SR, Rodriguez PL, Marquez JA (2009) The abscisic acid receptor PYR1 in complex with abscisic acid. Nature 462(7273): 665-668

Schneider CA, Rasband WS, Eliceiri KW (2012) NIH Image to ImageJ: 25 years of image analysis. Nat Meth 9(7):671-675

Siefers N, Dang KK, Kumimoto RW, Bynum WET, Tayrose G, Holt BF III (2009) Tissue-specific expression patterns of Arabidopsis NF-Y transcription factors suggest potential for extensive combinatorial complexity. Plant Physiol 149(2):625-641

Sinha S, Kim IS, Sohn KY, de Crombrugghe B, Maity SN (1996) Three classes of mutations in the A subunit of the CCAATbinding factor $\mathrm{CBF}$ delineate functional domains involved in the three-step assembly of the CBF-DNA complex. Mol Cell Biol 16(1):328-337

Stephenson TJ, McIntyre CL, Collet C, Xue GP (2007) Genome-wide identification and expression analysis of the $N F-Y$ family of transcription factors in Triticum aestivum. Plant Mol Biol 65(1-2):7792

Stephenson TJ, McIntyre CL, Collet C, Xue GP (2010) TaNF-YC11, one of the light-upregulated $N F-Y C$ members in Triticum aestivum, is co-regulated with photosynthesis-related genes. Funct Integr Genom 10(2):265-276

Tamura K, Peterson D, Peterson N, Stecher G, Nei M, Kumar S (2011) MEGA5: molecular evolutionary genetics analysis using maximum likelihood, evolutionary distance, and maximum parsimony methods. Mol Biol Evol 28(10):2731-2739

Thirumurugan T, Ito Y, Kubo T, Serizawa A, Kurata N (2008) Identification, characterization and interaction of HAP family genes in rice. Mol Genet Genom: MGG 279(3):279-289

Ulmasov T, Hagen G, Guilfoyle TJ (1999) Activation and repression of transcription by auxin-response factors. Proc Natl Acad Sci U S A 96(10):5844-5849

Umezawa T, Sugiyama N, Mizoguchi M, Hayashi S, Myouga F, Yamaguchi-Shinozaki K, Ishihama Y, Hirayama T, Shinozaki K (2009) Type 2C protein phosphatases directly regulate abscisic acid-activated protein kinases in Arabidopsis. Proc Natl Acad Sci U S A 106(41):17588-17593

Vlad F, Rubio S, Rodrigues A, Sirichandra C, Belin C, Robert N, Leung J, Rodriguez PL, Lauriere C, Merlot S (2009) Protein phosphatases 2C 
regulate the activation of the Snf1-related kinase OST1 by abscisic acid in Arabidopsis. Plant Cell 21(10):3170-3184

Warpeha KM, Upadhyay S, Yeh J, Adamiak J, Hawkins SI, Lapik YR, Anderson MB, Kaufman LS (2007) The GCR1, GPA1, PRN1, NF$Y$ signal chain mediates both blue light and abscisic acid responses in Arabidopsis. Plant Physiol 143(4):1590-1600

Wenkel S, Turck F, Singer K, Gissot L, Le Gourrierec J, Samach A, Coupland G (2006) CONSTANS and the CCAAT box binding complex share a functionally important domain and interact to regulate flowering of Arabidopsis. Plant Cell Online 18(11):2971-2984

West M, Yee KM, Danao J, Zimmerman JL, Fischer RL, Goldberg RB, Harada JJ (1994) LEAFY COTYLEDON1 is an essential regulator of late embryogenesis and cotyledon identity in Arabidopsis. Plant Cell 6(12):1731-1745

Winter D, Vinegar B, Nahal H, Ammar R, Wilson GV, Provart NJ (2007) An "Electronic Fluorescent Pictograph" browser for exploring and analyzing large-scale biological data sets. PLoS One 2(8):e718

Xing Y, Fikes JD, Guarente L (1993) Mutations in yeast HAP2/HAP3 define a hybrid CCAAT box binding domain. EMBO J 12(12):4647-4655

Xing Y, Zhang S, Olesen JT, Rich A, Guarente L (1994) Subunit interaction in the CCAAT-binding heteromeric complex is mediated by a very short alpha-helix in HAP2. Proc Natl Acad Sci U S A 91(8):3009-3013
Yamamoto A, Kagaya Y, Toyoshima R, Kagaya M, Takeda S, Hattori T (2009) Arabidopsis NF-YB subunits LEC1 and LEC1-LIKE activate transcription by interacting with seed-specific ABRE-binding factors. Plant J 58(5):843-856

Yoshida T, Fujita Y, Sayama H, Kidokoro S, Maruyama K, Mizoi J, Shinozaki K, Yamaguchi-Shinozaki K (2010) AREB1, AREB2, and $\mathrm{ABF} 3$ are master transcription factors that cooperatively regulate ABRE-dependent ABA signaling involved in drought stress tolerance and require $\mathrm{ABA}$ for full activation. Plant J 61(4):672-685

Zanetti ME, Blanco FA, Beker MP, Battaglia M, Aguilar OM (2010) A C subunit of the plant nuclear factor $N F-Y$ required for rhizobial infection and nodule development affects partner selection in the common bean-Rhizobium etli symbiosis. Plant Cell 22(12):4142-4157

\section{Funding}

This research was supported by the National Science Foundation (grant numbers IOS-0920258 and IOS-1149822). The National Science Foundation had no role in the study design, data collection and analysis, decision to publish, or preparation of the manuscript. 